\title{
Transplantation of mouse HSCs genetically modified to express a CD4-restricted TCR results in long-term immunity that destroys tumors and initiates spontaneous autoimmunity
}

\author{
Sung P. Ha, ${ }^{1}$ Nicholas D. Klemen, ${ }^{1}$ Garrett H. Kinnebrew, ${ }^{1}$ Andrew G. Brandmaier, ${ }^{1}$ \\ Jon Marsh, ${ }^{1}$ Giao Hangoc, ${ }^{1}$ Douglas C. Palmer, ${ }^{2}$ Nicholas P. Restifo, ${ }^{2}$ \\ Kenneth Cornetta, ${ }^{1}$ Hal E. Broxmeyer, ${ }^{1}$ and Christopher E. Touloukian' ${ }^{1}$ \\ 1Indiana University School of Medicine, Indianapolis, Indiana, USA. ${ }^{2}$ Surgery Branch, National Cancer Institute, Bethesda, Maryland, USA.
}

\begin{abstract}
The development of effective cancer immunotherapies has been consistently hampered by several factors, including an inability to instigate long-term effective functional antitumor immunity. This is particularly true for immunotherapies that focus on the adoptive transfer of activated or genetically modified mature $\mathrm{CD8}^{+} \mathrm{T}$ cells. In this study, we sought to alter and enhance long-term host immunity by genetically modifying, then transplanting, mouse HSCs. We first cloned a previously identified tumor-reactive HLA-DR4-restricted $\mathrm{CD}^{+}$TCR specific for the melanocyte differentiation antigen tyrosinase-related protein 1 (Tyrp1), then constructed both a high-expression lentivirus vector and a TCR-transgenic mouse expressing the genes encoding this TCR. Using these tools, we demonstrated that both mouse and human HSCs established durable, highefficiency TCR gene transfer following long-term transplantation into lethally irradiated mice transgenic for HLA-DR4. Recipients of genetically modified mouse HSCs developed spontaneous autoimmune vitiligo that was associated with the presence of a Th1-polarized memory effector $\mathrm{CD} 4^{+} \mathrm{T}$ cell population that expressed the Tyrp1-specific TCR. Most importantly, large numbers of $\mathrm{CD}^{+} \mathrm{T}$ cells expressing the Tyrp1-specific TCR were detected in secondary HLA-DR4-transgenic transplant recipients, and these mice were able to destroy subcutaneously administered melanoma cells without the aid of vaccination, immune modulation, or cytokine administration. These results demonstrate the creation of what we believe to be a novel translational model of durable lentiviral gene transfer that results in long-term effective immunity.
\end{abstract}

\section{Introduction}

A major obstacle in the development of effective cancer immunotherapies has been the inability to instigate long-term effective functional antitumor immunity. Recent clinical studies involving adoptive transfer of $\mathrm{T}$ cells into transiently myelodepleted hosts, though startling in their capacity to induce tumor regression, have been consistently hampered by the relative short-term lifespan of tumor-specific T cells $(1,2)$.

Given these limitations, current immunotherapies have sought to improve $\mathrm{T}$ cell durability by shifting the emphasis from demonstrable high-level in vitro reactivity to early-differentiation $\mathrm{T}$ cell phenotypes. This conceptual change in the approach to cancer immunotherapy is supported by evidence of a progressive pathway of $\mathrm{T}$ cell differentiation. Phenotypic changes in early to late effector $T$ cells are associated with diminished in vivo effector function and persistence $(3,4)$. Current strategies involving adoptive transfer of naive, central memory, or stem cell memory $\mathrm{T}$ cell populations have sought to take advantage of this continuum of functional change (5-8). Despite these advances, however, it remains unclear what the stability and long-term immune reactivities of these populations will be, and how they can be translated to patient care.

While most immunotherapies have emphasized $\mathrm{CD}^{+} \mathrm{T}$ cell responses, there is nearly overwhelming evidence to support the

Conflict of interest: The authors have declared that no conflict of interest exists. Citation for this article: $J$ Clin Invest. 2010;120(12):4273-4288. doi:10.1172/JCI43274. crucial role of $\mathrm{CD}^{+} \mathrm{T}$ helper cells in antitumor immunity $(9,10)$. Murine studies have consistently demonstrated that $\mathrm{CD}^{+} \mathrm{T}$ cells exert effects through induction and maintenance of $\mathrm{B}$ cells and $\mathrm{CD}^{+} \mathrm{T}$ cells, trigger long-term maintenance of antigen-activated memory $\mathrm{CD}^{+} \mathrm{T}$ cells $(11,12)$, and, when of sufficiently high avidity, overcome host Tregs (13). There is also evidence that combined administration of class I and II epitopes derived from the same tumor antigen can potentiate antitumor immunity $(14,15)$. Despite these strongly supportive data, very few studies have used $\mathrm{CD}^{+} \mathrm{T}$ cells as the principal driving force of therapy $(16,17)$.

Given limitations with existing cancer immunotherapies, we sought to establish a model of long-term immunity characterized by a durable, high-frequency population of permanently unmanipulated tumor-reactive $\mathrm{CD}^{+} \mathrm{T}$ cells. New technologies in lentiviral (LV) gene transfer have allowed for the introduction of large genetic elements into mitotically quiescent HSCs (18). To design a model of TCR gene transfer, we utilized a previously identified autoreactive, melanomareactive HLA-DRB1*0401-restricted (HLA-DR4-restricted), tyrosinase-related protein 1-specific (Tyrp1-specific or TRP-1-specific) $\operatorname{TCR}(13,19)$. Tyrp1, a melanosomal protein present in normal melanocytes and melanomas, has been exploited as an immunotherapeutic target in several animal models, inducing both autoimmune vitiligo (20-22) and eradication of established tumors $(13,23)$. We then generated a new lentivector expressing the $\alpha$ and $\beta$ TCR subunits and a TCR Tg expressing the same TCR genes. Herein, we demonstrate durable, high-efficiency TCR gene transfer in similarly executed iso- 
congenic HSC transplants following 12-month primary and 6-month secondary transplants. We then demonstrate induction of spontaneous autoimmune vitiligo and destruction of subcutaneous B16 melanoma without the aid of vaccination, cytokine administration, or immune modulation. To more fully reveal the translational patient care potential of this model, we also demonstrate long-term TCR gene expression in humanized HSC transplants.

\section{Results}

Tyrp1-specific TCR is highly expressed and functional in vitro. To develop a model of TCR transfer into HSCs, we cloned TCR $\alpha / \beta$ genes from a previously identified Tyrp1-specific, tumor reactive HLADRB1*0401-restricted (HLA-DR4-restricted) CD4 ${ }^{+} \mathrm{T}$ cell from a patient with metastatic melanoma (19) using previously described cloning methodology $(24,25)$ : TCR- $\alpha$ : V $\alpha 13-2 * 01$, J2 $2 * 01$; TCR- $\beta$ : $\mathrm{V} 5.4 * 01, \mathrm{~J} 1-1 * 01, \mathrm{D} 1 * 01$. We then constructed 2 separate highexpression, self-inactivating (SIN) lentivectors to deliver TCR genes to HSCs. Two strategies were employed for expressing TCR chains on either a bicistronic or monocistronic message driven by the same heterologous promoter (CMV). For the first strategy, TCR $\alpha$ and $\beta$ chains were co-expressed using the IRES element (26, 27). The second involved replacing the IRES sequence with a Furin cleavage site fused to a post-translational $2 \mathrm{~A}$ self-cleaving peptide (28). This strategy has been used to boost expression of the second gene with combined Ig heavy and light chain genes by creating a single, long post-translationally cleaved gene product.

To evaluate the efficiency and functionality of TCR gene transfer, we tested the newly generated LV-TCRs (LV-TCR-IRES or LV-TCRF2A) on human PBMCs prestimulated with IL-7 (29). We used a

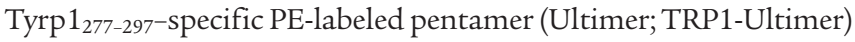
to measure specific cell surface expression, to avoid confusing true expression levels of the introduced $\alpha / \beta$ heterodimer with levels that result from mispairings with endogenous $\mathrm{T}$ cell $\alpha$ and $\beta$ chains. As shown in Figure 1A, we observed statistically significant differences in TCR gene expression using the LV-TCR-F2A construct at increasing viral titers ( $37.5 \%$ vs. $56.4 \% ; P=0.0008$ at MOI 30 ).

To evaluate in vitro functionality of the LV-TCR-F2A lentivector (hereafter referred to as LV-TCR), we transduced IL-7-prestimulated PBMCs at an MOI of 15 . After 24 hours, a standard coculture and ELISA assay were prepared against targets. As shown in Figure $1 \mathrm{~B}$, we observed specific IFN- $\gamma$ secretion (and GM-CSF, but not IL-4; data not shown) to specific peptide (Tyrp1 $277-297)$, lysate (B16), and intact tumors (B16-DR4, $624 \mathrm{Mel}$ pretreated with IFN- $\gamma$, and 1102 Mel stably transduced with Tyrp1), but not to either control peptide $\left(\mathrm{HA}_{306-318}\right)$, control lysate (MC38), or control tumors (wildtype B16, MC38-DR4, and $1102 \mathrm{Mel}$ stably transduced with GFP). Interactions with peptide-pulsed targets were both DR restricted (blocked by L243) and CD4 specific (blocked by L3T4), but were not affected by control MHC class I- and CD8-specific antibodies.

To determine relative efficiency of gene transfer for future transplants, we designed TCR-transgenic (TCR Tg) mice expressing the same variable human $\alpha$ and $\beta$ genetic components as used in the LV-TCR. Founder mice were screened by PCR, then crossed with both standard C57BL/6 mice and DR4 Tg mice to create 2 experimental groups to study TCR expression and to serve as a source of HSCs for future transplants. TCR Tg mice differed from those used in the LV-TCR, in that constant regions of both chains were murine and TCR expression was under the control of endogenous TCR promoter/enhancer elements (30). As shown in Figure 1, C and D, mice crossed onto a HLA-DR4 background strongly expressed spe- cific TCR $\left(\mathrm{CD}^{+} /\right.$Ultimer $^{+}, 79 \% \pm 8.3 \%$ ), while those on a C57BL/6 background expressed low levels only $\left(\mathrm{CD}^{+} /\right.$Ultimer $^{+}, 6.4 \% \pm 1.0 \%$; $P<0.0001)$. These results strongly suggested the necessity of a proper restriction element (HLA-DR4) in positive T cell selection. To control for experimental specificity and background $(<1 \%)$, we used a pentamer specific for gp $100_{44-59}$ DR4-restricted T cells (Ultimer-gp100) (31). This multimeric peptide antibody control was used for all subsequent flow cytometry analyses.

$L V$ gene-modified HSCs enact functional long-term engraftment and repopulation in transplant recipients. To quantify the engraftment potential, gene transfer efficiency, and long-term stability of transduced HSCs, we assessed a competitive CD45.1/CD45.2 repopulation. Boy-J (CD45.1) lineage-depleted ( Lin $\left.^{-}\right)$donor cells (>95\% Lin; data not shown) were transduced with concentrated $L V$ supernatant from LV-TCR, then combined (following an overnight recovery) at a total of $5 \times 10^{4}$ cells with unfractionated isocongenic BM (CD45.2, $2.5 \times 10^{5}$ cells) from DR4 Tg mice, before transplantation by tail vein injection into lethally irradiated (990 cGY) DR4 Tg recipients (5-10 mice/group/experiment). Similarly prepared and prestimulated control transplants (of both nontransduced and LV-GFP transduced cells) were also assessed. To investigate TCR gene transfer efficiency, a parallel group involving prestimulated Lin $^{-}$cells $\left(5 \times 10^{4}\right)$ from TCR Tg mice were combined with unfractionated BM cells $\left(2.5 \times 10^{5}\right)$ from DR4 Tg mice and similarly transplanted into irradiated DR4 Tg recipients (5-10 mice per experiment). An overview of the transplant procedure is shown in Figure 2A.

Beginning at 1 month after transplantation, peripheral blood (PB) was stained (at multiple time points) with fluorochrome-conjugated antibodies specific for murine CD45, CD4, CD8, CD3, and the TRP1-Ultimer. As shown in Figure 2B, LV-TCR gene-specific CD4 ${ }^{+}$ T cells were identified at a level of $53 \%\left(\mathrm{CD} 5^{+} / \mathrm{CD}^{+} / \mathrm{CD}^{+} / \mathrm{Ultimer}^{+}\right)$ at 6 months and at a level of $28 \%$ at 12 months after transplantation. This compared with a level of $78 \%\left(\mathrm{CD} 45^{+} / \mathrm{CD}^{+} / \mathrm{CD}^{+} / \mathrm{Ultimer}^{+}\right)$at 6 months and $69 \%$ at 12 months in the TCR Tg group. As seen in Figure $2 \mathrm{C}$, the majority of $\mathrm{CD}^{+}{ }^{+}$Ultimer $^{+}$cells were also found to be $\mathrm{CD}^{+}$, with less than $5 \% \mathrm{CD}^{+}$cells, suggesting that co-expression of CD4 was essential for specific TCR selection. In addition, as shown in Figure 2D, 12-month PB samples were found to co-express the endogenous murine TCR $\beta$ (mTCR $\beta$ ) chain (consistently >95\%) in both $\mathrm{CD}^{+}{ }^{+} \mathrm{Ultimer}^{+}$and $\mathrm{CD} 4^{+} \mathrm{Ultimer}^{-}$subpopulations. We did, however, find statistically significant differences in MFI between the 2 populations ( $224 \pm 44$ vs. $577 \pm 46 \mathrm{MFI} ; P=0.0005$ ), suggesting a lower density of mTCR on those cells shared by the TCR transgene (see Supplemental Figure 1; supplemental material available online with this article; doi:10.1172/JCI43274DS1). Lastly, we found no significant difference in frequency of Tregs $\left(\mathrm{CD} 4^{+} \mathrm{CD} 25^{+} \mathrm{Foxp} 3^{+}\right)$ between control and LV-TCR transplants, including those subpopulations that were Ultimer ${ }^{+}$and Ultimer- (see Supplemental Figure 2, $A$ and B). Calculations for all displayed results were based on combined CD45.1 and CD45.2 gates to more accurately quantify TCR gene expression within the entire T cell compartment.

In general, TCR-specific levels were consistently and statistically higher at 1, 2, 4, 6, and 12 months after transplantation in the TCR Tg group compared with the LV-TCR group. These overall findings were observed within the total cellular compartment (Figure 3A; $\mathrm{CD} 45^{+}$Ultimer $^{+}$), the global $\mathrm{T}$ cell compartment (Figure 3B; $\mathrm{CD} 5^{+} \mathrm{CD}^{+}{ }^{+}$Ultimer $^{+}$), and the $\mathrm{CD}^{+} \mathrm{T}$ cell subpopulation (Figure 3C; $\mathrm{CD}_{4} 5^{+} \mathrm{CD}^{+}{ }^{+} \mathrm{CD} 4^{+}$Ultimer $\left.^{+}\right)$. Levels of TCR-specific $\mathrm{CD}^{+}$ $T$ cells reached their peak (in the LV-TCR group) at 6 months after transplantation, before diminishing in frequency by 12 months 

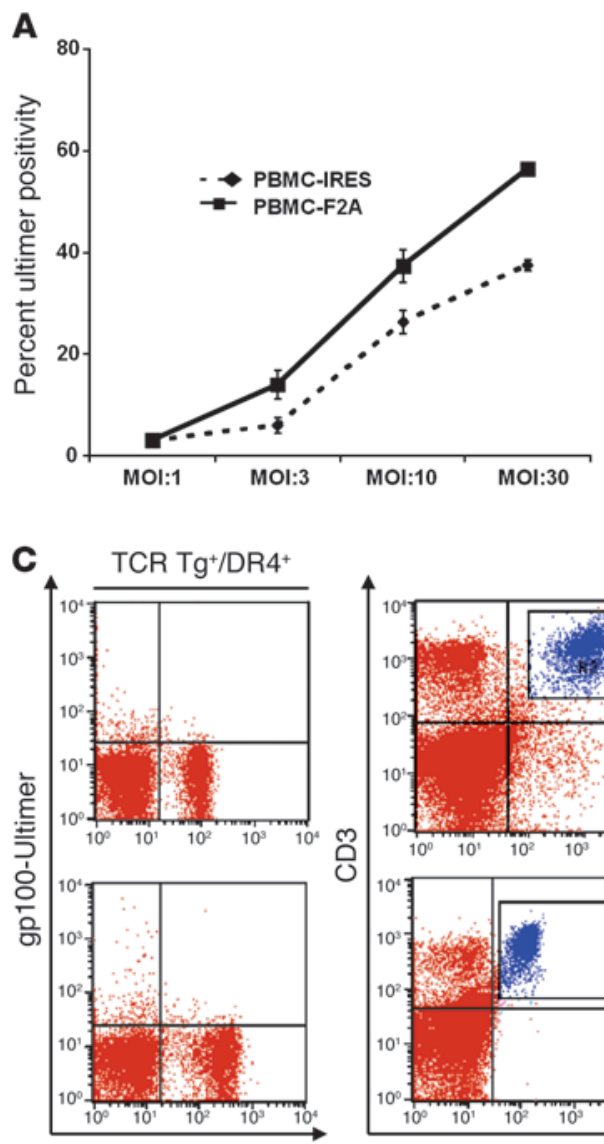

CD3 (t) CD4 (b)

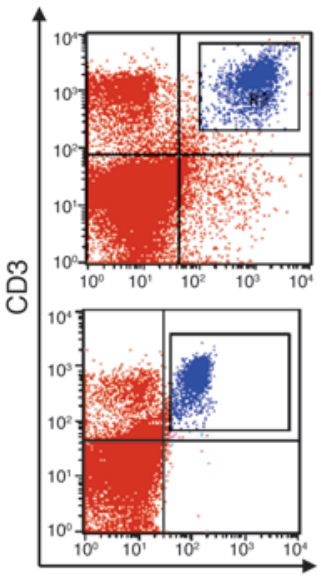

CD4
B

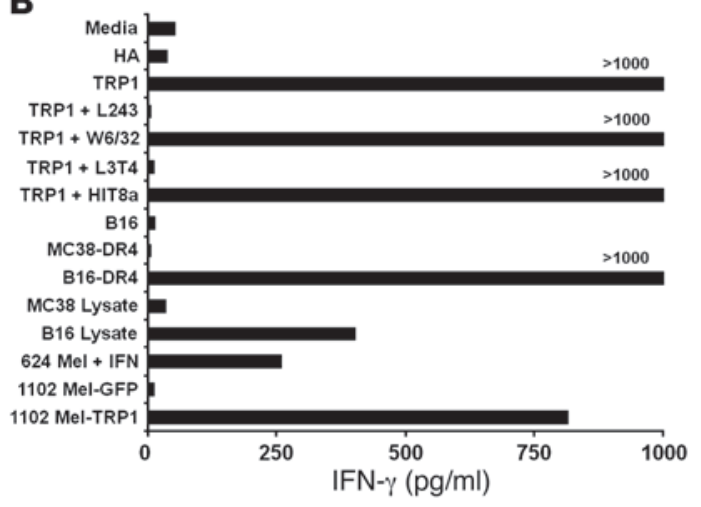

D

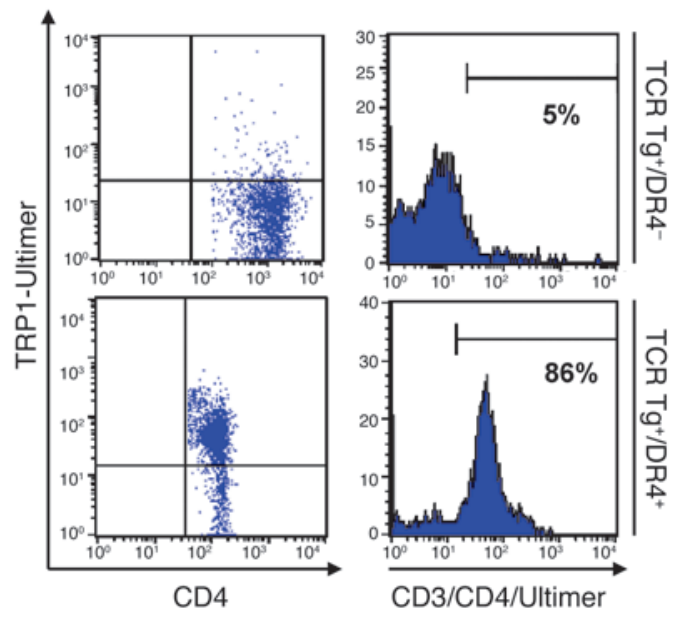

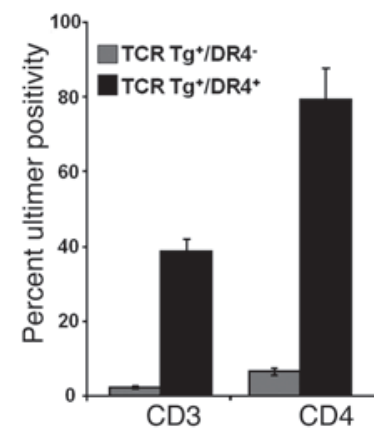

Figure 1

DR4-restricted, Tyrp1-specific TCR is expressed and functional. (A) At an increasing viral MOI, lentivector containing the F2A gene was superior to IRES in generating stable TCR heterodimers in human PBMCs. Cell surface expression of the Tyrp1-specific TCR was determined by flow cytometry using a PE-labeled DR4 Ultimer containing the Tyrp $1_{277-297}$ epitope. At MOI $30: 37.5 \% \pm 1.5 \%$ versus $56.4 \% \pm 1.1 \%(P=0.0008)$. hCD 45 , human CD45. (B) PBMCs transduced with LV-TRP1-F2A (LV-TCR) were functionally specific. Specific IFN- $\gamma$ production detected by ELISA to the specific peptide (Tyrp1 $277-297$ ), lysate (B16 lysate), and intact tumors (B16-DR4, 624 Mel pretreated with IFN- $\gamma$, and 1102 Mel stably transduced with Tyrp1), but not to the control peptide $\left(\mathrm{HA}_{306-318}\right)$, lysate (MC38), or tumors (wild-type B16, MC38-DR4, and 1102 Mel stably transduced with GFP). Interactions with Tyrp1 $1_{277-297}$-pulsed targets were blocked by L243 (HLA-DR) and L3T4 (CD4), but not W6/32 (class I) or HIT8a (CD8) antibodies. Peptides were pulsed onto DR4 ${ }^{+} 1088$ EBV-B cells at $50 \mu \mathrm{M}$ for 3 hours. Txp, transplant. (C) TCR Tg mice crossed with DR4 Tg mice strongly expressed the gene-specific TCR. Flow cytometry analysis (CD3/CD4/Tyrp1 Ultimer) of TCR+DR4+ and TCR ${ }^{+} D R 4^{-}$mice. Control staining

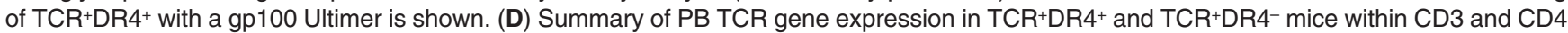
compartments: CD4, $79 \% \pm 8.3 \%$ versus $6.4 \% \pm 1.0 \% ; P<0.0001$. Data (mean \pm SEM with $P$ value; $n=5-7$ per group) and flow cytometry are representative of $2-3$ independent experiments.

$(52.3 \% \pm 2.0 \%$ at 6 months vs. $26.1 \% \pm 2.4 \%$ at 12 months; $P=0.004)$. These results contrasted with those from the TCR Tg group, in which gene expression was statistically unchanged from 6 to 12 months $(74.3 \% \pm 5.5 \%$ at 6 months vs. $65.2 \% \pm 6.3 \%$ at 12 months; $P=0.19)$ and statistically nonsignificant from levels in the endogenous nontransplanted population (see Figure 1C; $79.3 \% \pm 8.3 \%$; $P=0.12$ ). The overall differences between groups were, therefore, contrasted by a long-term rate of genetic stability in the TCR Tg group. Given these findings, and to evaluate overall transplant efficiency (itself a function of LV gene transfer efficiency and LV gene stability), we measured TCR gene efficiency as a function of TCR expression positivity $(\%=$ LV-TCR/TCR-Tg $\times 100)$ within the total CD3 and CD4 compartments. Efficiency peaked in both populations at 6 months (CD3, 53\%; CD4, 70\%) before trailing off by 12 months (CD3, 48\%; CD4, 40\%) (see Figure 3D).
To more specifically gauge TCR gene expression that developed from LV-TCR-transduced CD 45.1 ${ }^{+} \mathrm{Lin}^{-}$cells, PB samples from 6and 12-month transplant samples were analyzed by flow cytometry. As shown in Figure 4, A and B, TCR gene-specific T cells represented a dominant fraction of all $\mathrm{CD}^{+}$and $\mathrm{CD} 4^{+}$lymphocytes within the CD45.1 compartment (at 12 months: CD3, 37\% $\pm 7.4 \%$; CD4, 54\% $\pm 7.8 \% ; P=0.04$ ). Overall, these results (total CD45 and CD45.1) are consistent with high-frequency, durable repopulation of gene-specific T cells derived from LV-transduced HSCs.

High-level TCR expression is identified within thymic subpopulations 1 year after transplantation. Early lymphoid progenitors travel to the thymus and undergo a complex, multi-step process of differentiation, proliferation, and repertoire selection (32). Although much of this process occurs early in mammalian life, there is increasing clinical and experimental evidence that thymopoietic activity undergoes 
A

\section{BM Harvest Lineage Depletion}

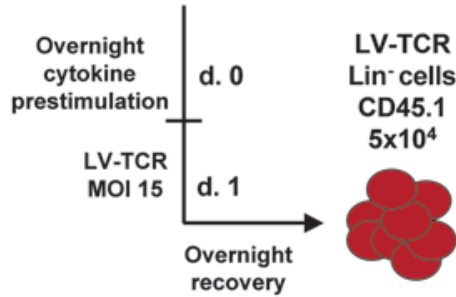

vs.

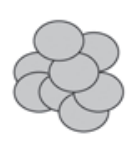

TCR TG

Lin cells

CD45.2

$5 \times 10^{4}$

B

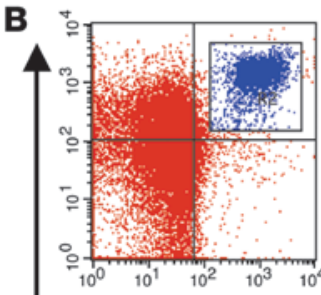

ำ
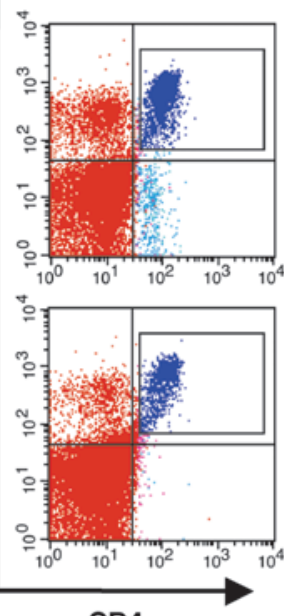

CD4
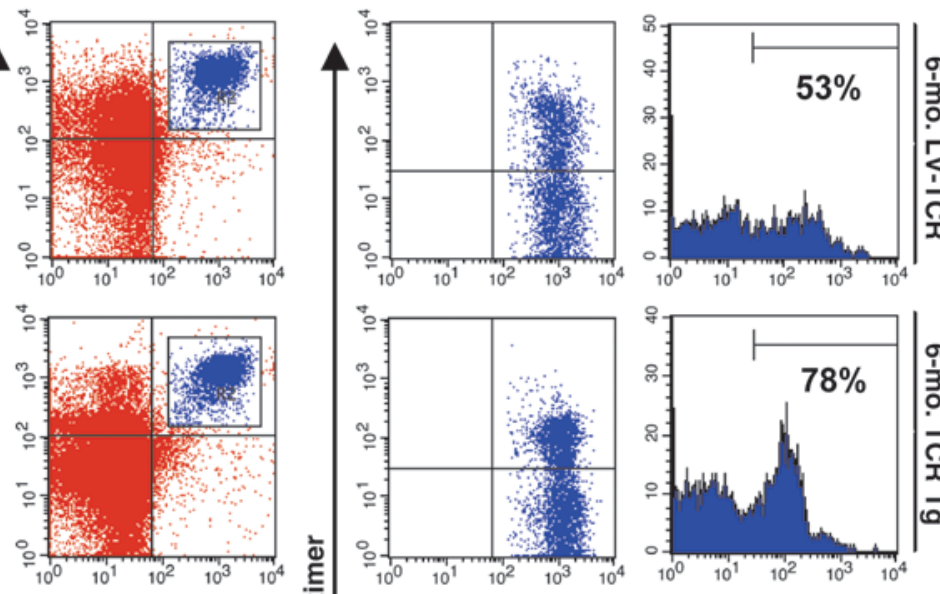

ํำ

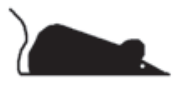

Unfractionated DR4 Tg BM CD45.2 $2.5 \times 10^{5}$

Transplantation DR4 Tg Mice $990 \mathrm{cGY}$

d. 2
C
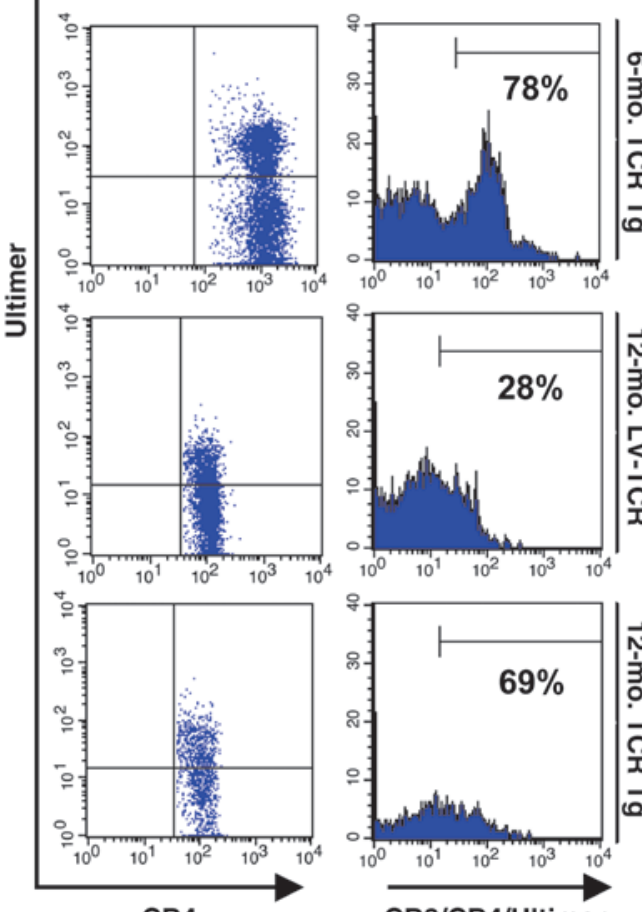

D
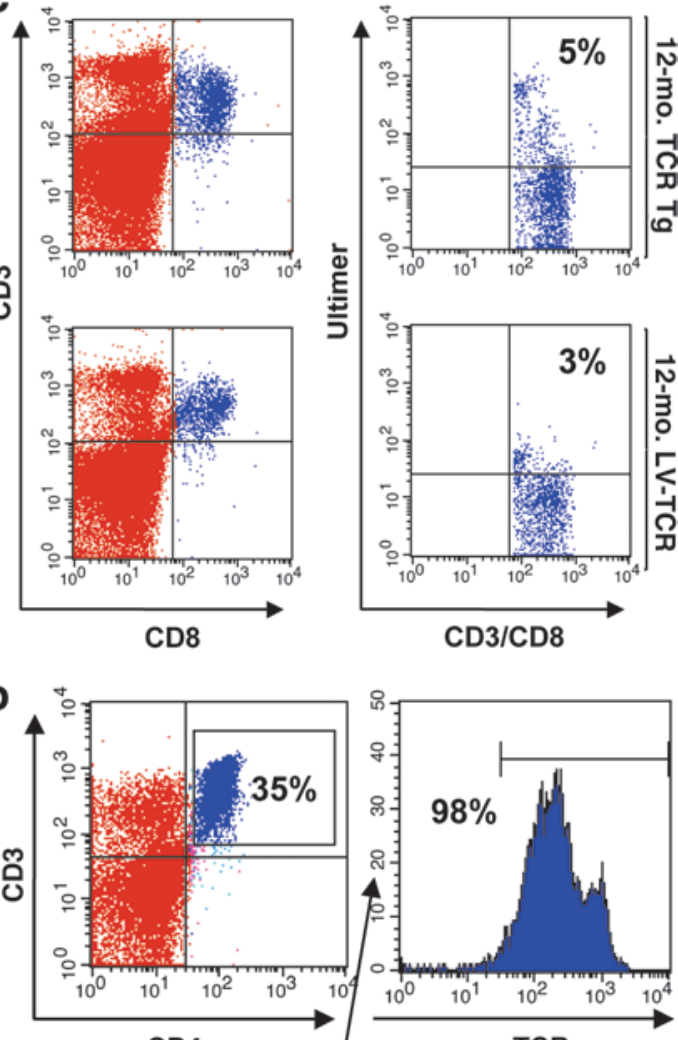

壳

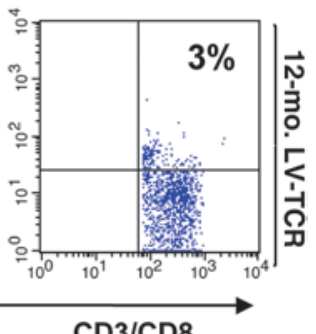

CD3/CD8

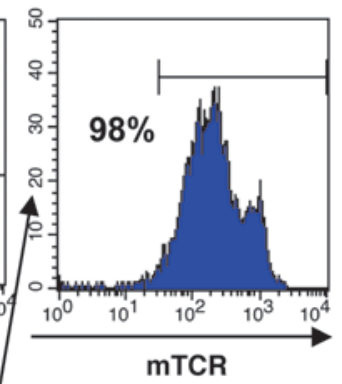

MTCR

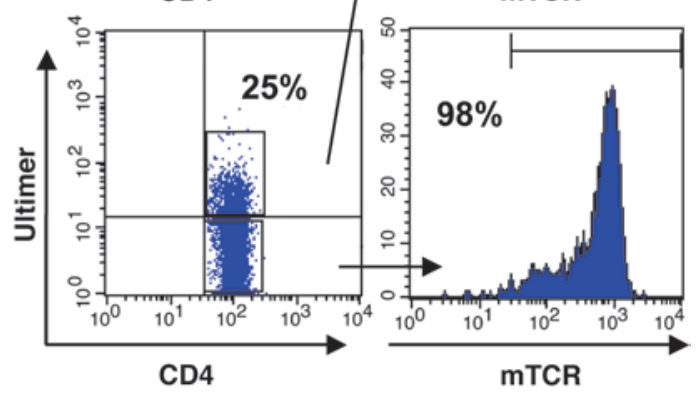

Figure 2

LV gene-modified HSCs functionally engraft and repopulate transplant recipients over the long term. (A) Overview of transplant procedure. Lincells were isolated and transduced with LV-TCR. Competitive reconstitution was performed using transduced Lin- cells (CD45.1, $\left.5 \times 10^{4}\right)$ combined with congenic BM cells $\left(C D 45.2,2.5 \times 10^{5}\right)$ from DR4 Tg mice, then transplanted into irradiated DR4 Tg recipients. A parallel arm involving Lin- cells $\left(5 \times 10^{4}\right)$ from TCR Tg mice combined with unfractionated BM $\left(2.5 \times 10^{5}\right)$ from DR4 transgenic mice was transplanted into similarly irradiated hosts. (B) Flow cytometry analysis of PB at 6 and 12 months demonstrated high-level TCR gene expression: CD45+CD3+CD4+Tyrp1 Ultimer staining of LV-TCR and TCR Tg transplant groups. (C) Flow cytometry analysis of PB at 12 months demonstrated low-level TCR gene expression within CD8 compartment: CD45 ${ }^{+} \mathrm{CD} 3^{+} \mathrm{CD} 8{ }^{+}$Tyrp1 Ultimer ${ }^{+}$staining of LV-TCR and TCR Tg transplant groups. (D) Flow cytometry analysis of PB at 12 months demonstrated high-level co-expression of the murine TCR $\beta$ chain in both CD4+Ultimer ${ }^{+}$and CD4 $^{+}{ }^{+}$ltimer ${ }^{-}$subpopulations. Data are representative of flow cytometry studies done on 4 separate transplant experiments. 

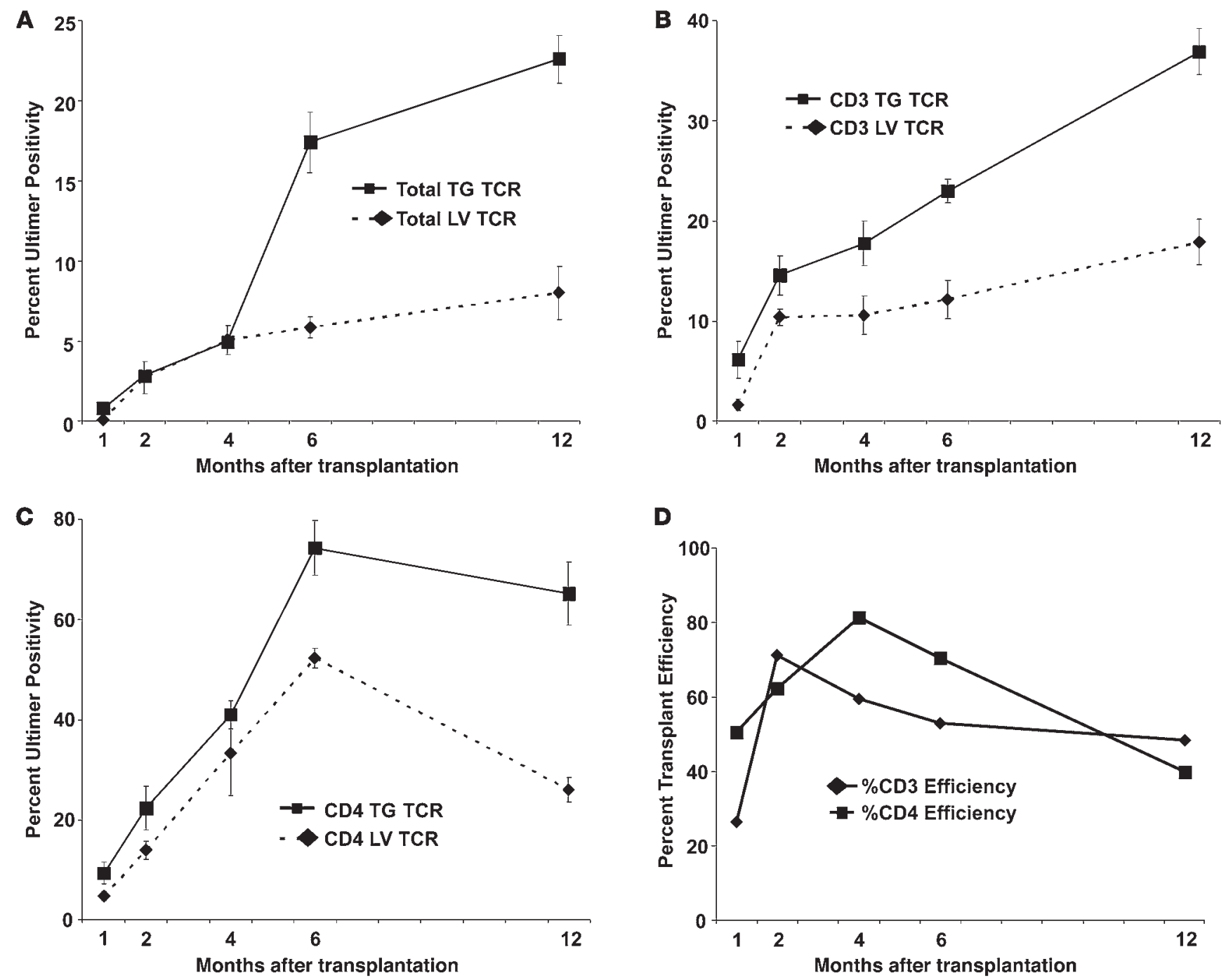

Figure 3

Summary results of 12-month primary transplants. (A) Twelve-month transplant summary of TCR gene expression in LV-TCR and TCR Tg groups within the total cellular compartment as measured by evaluation of 10,000 gated events from PB. At 12 months, $8 \% \pm 1.7 \%$ versus $22.6 \% \pm 1.5 \% ; P=0.001$. (B) Twelve-month transplant summary of TCR gene expression in LV-TCR and TCR Tg groups within CD3 compartment. At 12 months, $17.8 \% \pm 2.3 \%$ versus $36.7 \% \pm 2.4 \% ; P=0.006$. (C) Twelve-month transplant summary of TCR gene expression in LV-TCR and TCR Tg groups within CD4 compartment. At 12 months, $26.1 \% \pm 2.4 \%$ versus $65.2 \% \pm 6.3 \% ; P=0.004$. (D) Twelve-month transplant summary of TCR gene transfer efficiency $(\%=$ LV-TCR/TCR $\mathrm{Tg} \times 100)$ within CD3 and CD4 compartments. Data (mean \pm SEM with $P$ value; $n=5-10$ per group) are representative of $3-4$ independent experiments.

substantial re-amplification (or "thymic rebound") well into late adult life (33). These findings are particularly true in patients successfully treated for HIV or following chemotherapy-induced lymphopenia and subsequent transplantation (34). Given our results that both the appropriate restriction element (HLA-DR4) and coreceptor expression (CD4, not CD8) are critical for TCR expression, we evaluated cellular density and compositional makeup of individual thymic subpopulations in 12-month-old transplant recipients (approximately 14 months overall age). In addition, we again sought to determine whether an intact endogenous murine TCR was co-expressed in thymic TCR-specific subpopulations.

From a cohort of 4-6 mice per experiment, 12 months post LV-TCR transplantation, thymocytes were analyzed by multicolor flow cytometry with fluorochrome antibodies to CD45,
CD3, CD4, CD8, murine TCR $\beta$, and the Tyrp1 Ultimer. Despite the advanced age of the mice, a high percentage of TCR-specific gene expression was observed in double-negative (DN), doublepositive (DP), and single-positive (SP) populations (see Figure 5, $\mathrm{A}-\mathrm{C}$ ), findings consistent with continued HSC production and thymic replenishment of gene-specific $\mathrm{T}$ cell progenitors. We also observed a steep and significant drop in TCR gene expression (DP, $45 \% \pm 7.3 \%$; SP CD $4,13.3 \% \pm 3.1 \%$; $P=0.002$ ), with no corresponding change in MFI, as thymocytes transitioned from DP to SP, which was consistent with partial central elimination

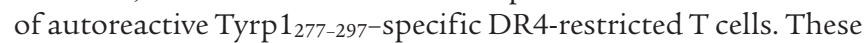
findings are in agreement with existing models of self-tolerance, in which autoreactive $T$ cells are eliminated within the thymus by medullary thymic epithelial cells that promiscuously express 
A
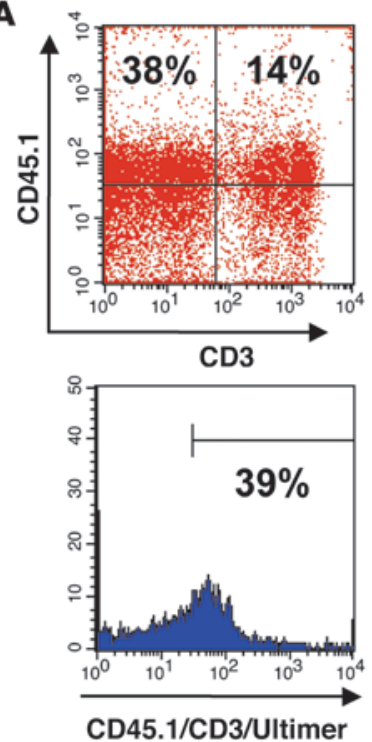
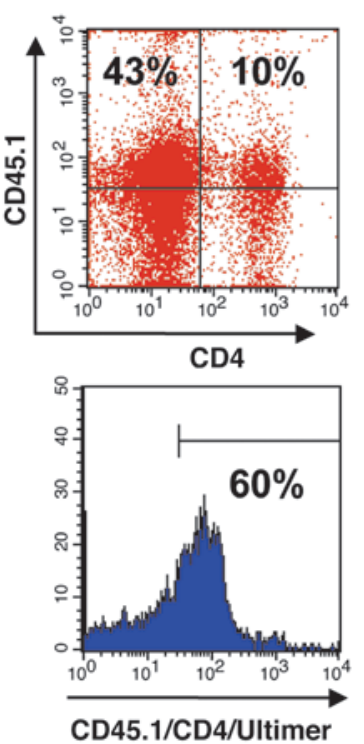

B

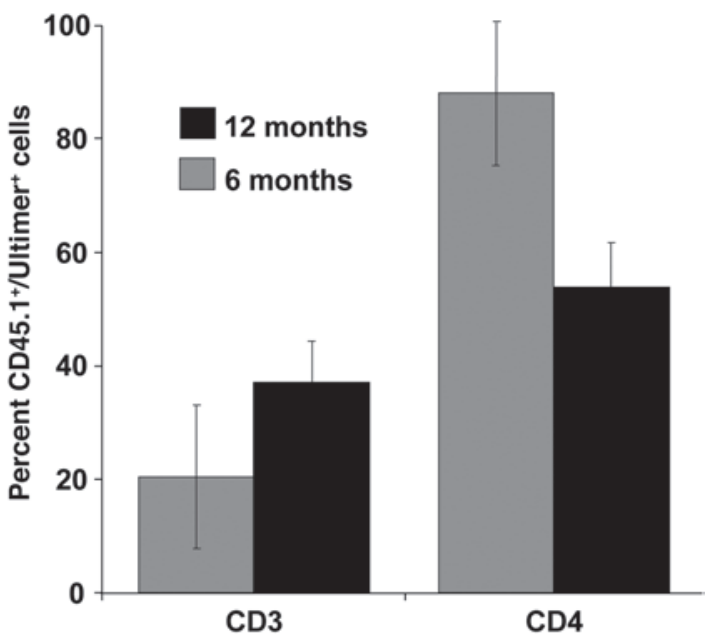

Figure 4

TCR gene-specific T cells represent a dominant fraction of all lymphocytes within the CD45.1 subcompartment. (A) Flow cytometry analysis of PB at 12 months post-transplantation demonstrated high-level TCR gene expression: CD45.1+CD3+Tyrp1 Ultimer ${ }^{+}$and CD45.1+CD4+Tyrp1 Ultimer $^{+}$staining of LV-TCR transplants. (B) Six- and 12-month transplant summary of TCR gene expression within the CD3 and CD4 subpopulation as a function of CD45.1-gated cells. At 12 months: CD3, 37\% $\pm 7.4 \%$; CD4, 54\% $\pm 7.8 \%$; $P=0.04$. Data (mean \pm SEM with $P$ value; $n=5-10$ per group) and flow cytometry are representative of 2 independent experiments.

cognate antigen, by thymic dendritic cells, or by cross-reactive peptides $(35,36)$. These finding are also supported in our own antigen model, in which higher-avidity $\mathrm{T}$ cells are generated in mice genetically deficient in Tyrp1 (13). Despite low systemic levels of gene-specific TCR within $\mathrm{CD}^{+} \mathrm{T}$ cells (see Figure 2D), expression of SP CD8 cells was similar to that of SP CD4 cells, suggesting selective elimination following thymic emigration into the periphery. Lastly, we found intact, overlapping co-expression of murine $\mathrm{CD} 3$, murine TCR $\beta$, and Tyrp1 Ultimer within SP CD 4 cells. These results again indicate autonomous dual TCR expression (both endogenous murine TCR complex and heterologous TCR transgene) within the same developing cell and are in agreement with our 12-month PB data (See Figure 2D).

Recipients develop spontaneous autoimmune vitiligo after transplant. Between 8 and 12 weeks after transplantation, LV-TCR mice were consistently found to develop progressive skin depigmentation or vitiligo, a finding not observed in control transplanted mice, including those transplanted with LV-GFP-transduced HSCs (see Figure 6). This pattern of depigmented skin bordered by areas with no apparent signs of pigment loss resembled vitiligo development in other models of Tyrp1 autoreactivity (20-23). Vitiligo development was also observed in mice transplanted with HSCs derived from TCR Tg mice, but not in endogenous, nontransplanted TCR Tg mice nor in transplanted mice lacking expression of HLA-DR4 (Table 1). These results suggest that myelodepletion and transplantation combined with specific immune reconstitution (either from LV gene-modified or Tg HSCs in combination with HLA-DR4 expression) provide appropriate conditions for development of autoimmune vitiligo.

To address the pathogenesis of autoimmune vitiligo, we analyzed both paraffin-embedded and liquid nitrogen-frozen skin samples from LV-TCR and control transplants by immunohistochemistry (IHC). As shown in Figure 7, subdermal hair follicle-based mela- nocytes were found obliterated, with effacement of normal architecture, based on staining with $\mathrm{H} \& \mathrm{E}$ (Figure 7, A and B) and S-100 (Figure 7, C and D). These findings were further supported by a dense infiltration of $\mathrm{CD}^{+} \mathrm{T}$ cells into the subdermal space in and around obliterated hair follicles (Figure 7, E and F). When frozen sections of identical skin samples were stained with antibodies to $\mathrm{CD} 4$ and $\mathrm{CD} 8$, only CD4 staining was observed (Figure 7, G and H). To determine whether TCR gene-specific $T$ cells were invading the subdermal compartment, sections were stained with an exclusively human TCR $\beta$-chain specific antibody (Figure 7I). As shown, staining was identical in both pattern and location to CD3 staining and distribution. To verify antibody specificity, human tonsil and mouse spleen samples were similarly analyzed and found to be positive and negative, respectively (data not shown).

Transplant recipients exbibit a memory-effector phenotype and react spontaneously to antigen. To further understand the pathogenesis behind post-transplant vitiligo, we investigated the activation status of TCR-specific $\mathrm{CD}^{+} \mathrm{T}$ cells. We had already observed that nontransplanted endogenous TCR Tg mice failed to develop vitiligo. Based on these findings, we hypothesized that post-transplant-specific $\mathrm{T}$ cells would exhibit surface-bound phenotypic features consistent with spontaneous immune activation $(37,38)$. To study this, PB from 6-month-old transplanted mice (LV-TCR and control) and naive TCR Tg mice was stained with fluorochrome-conjugated antibodies specific for CD4, Tyrp1 Ultimer, CD44, CD45RB, and CD62L, then analyzed by multicolor flow cytometry to determine percent specific frequency. As shown in Figure 8, A and B, LV-TCR transplant $\mathrm{CD}^{+}{ }^{+}$Ultimer ${ }^{+}$cells exhibited a memory effector $\mathrm{T}$ cell $\left(\mathrm{T}_{\mathrm{EM}}\right)$ profile $\left(\mathrm{CD} 44^{\mathrm{hi}} \mathrm{CD} 45 \mathrm{RB}^{\mathrm{lo}} \mathrm{CD} 62 \mathrm{~L}^{\mathrm{lo}}\right)$, in contrasted to control transplant $\mathrm{CD} 4^{+} \mathrm{T}$ cells, which exhibited a more generalized effector profile (CD44 $\left.{ }^{\text {hi }} \mathrm{CD} 45 \mathrm{RB}^{\mathrm{hi}} \mathrm{CD} 62 \mathrm{~L}^{\mathrm{int}}\right)$, and in greater contrast to naive $\mathrm{CD}^{+}{ }^{+}$Ultimer $^{+} \mathrm{T}$ cells $\left(\mathrm{CD} 44^{\mathrm{lo}} \mathrm{CD} 45 \mathrm{RB}^{\mathrm{hi}} \mathrm{CD} 62 \mathrm{~L}^{\mathrm{hi}}\right)$ obtained from 
A
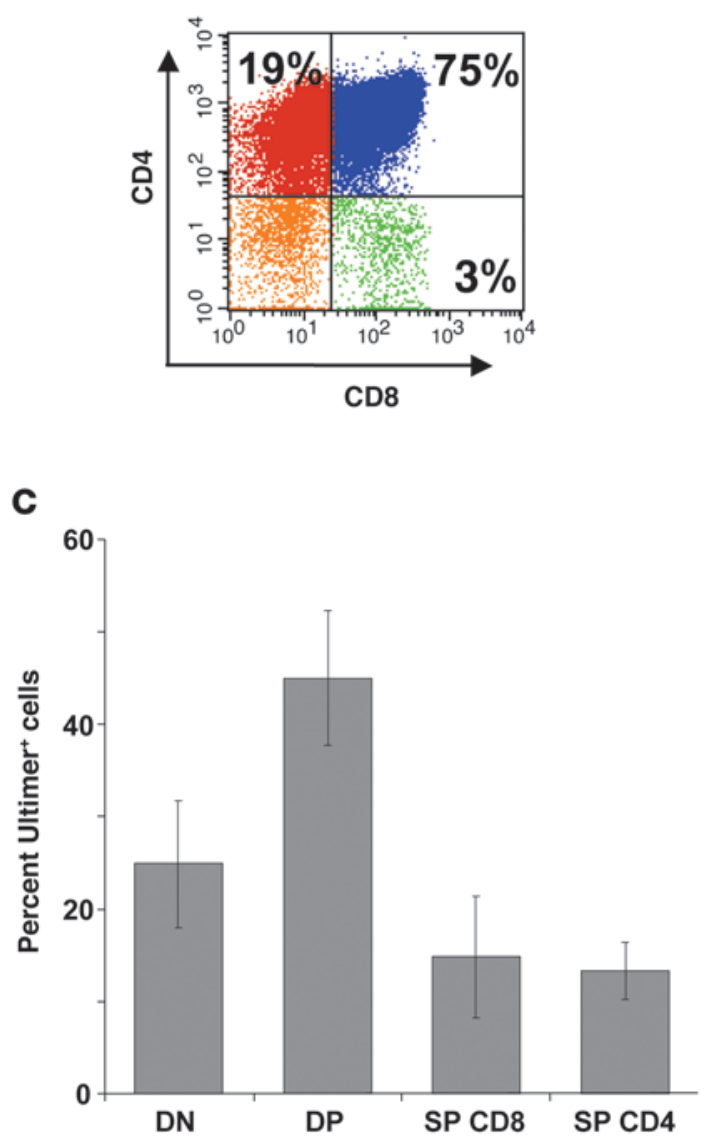

B
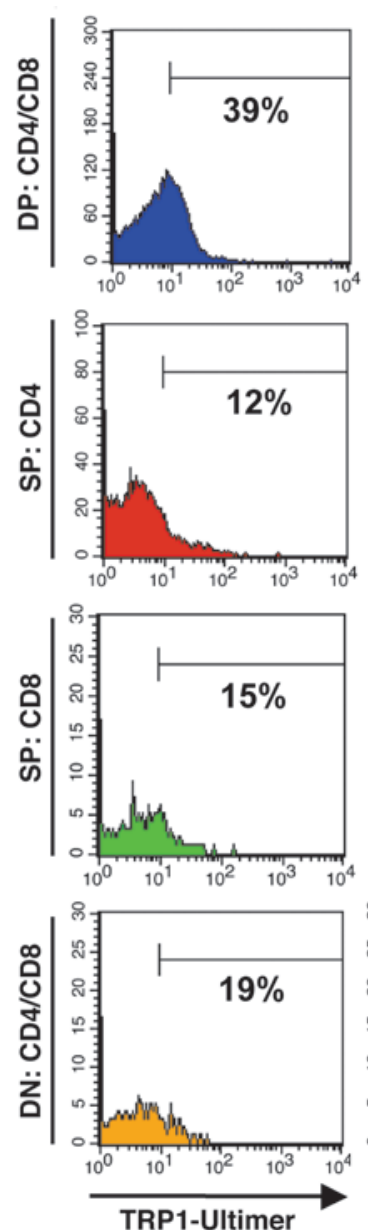
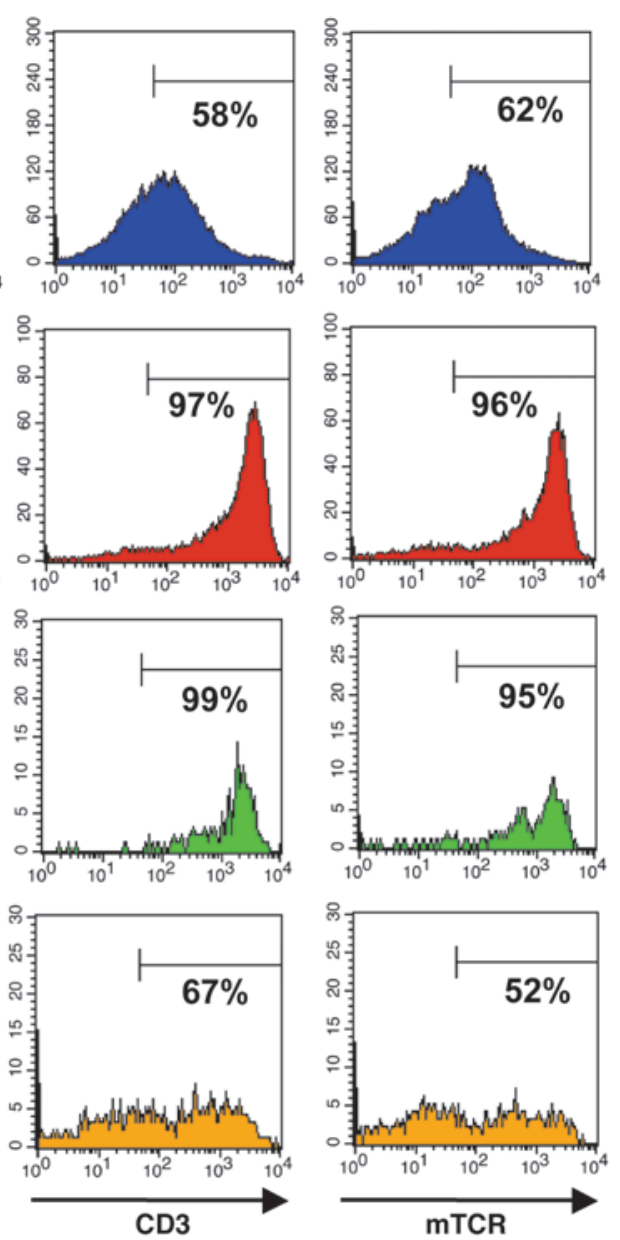

Figure 5

One year after transplantation, high-level TCR expression is identified within thymocyte subpopulations. (A and B) Flow cytometry analysis of thymocytes at 12 months after LV-TCR transplantation demonstrated intact co-expression of endogenous murine TCR complex and TCR transgene within SP, DP, and DN subpopulations: $\mathrm{CD}_{4} 5^{+}, \mathrm{CD}^{+}, \mathrm{CD}^{+}, \mathrm{CD} 8^{+}$, murine TCR $\beta^{+}$, and Tyrp1 Ultimer ${ }^{+}$staining. (C) Summary of TCR gene expression in DN, DP, SP CD8, and SP CD4 subpopulations: DP $45 \% \pm 7.3 \%$ versus SP CD4 $13.3 \% \pm 3.1 \% ; P=0.002$. Data (mean \pm SEM with $P$ value; $n=4-6$ per group) and flow cytometry are representative of 3 independent experiments.

endogenous, nontransplanted TCR Tg mice. The CD4+Ultimer ${ }^{-}$ subpopulation was similar in its expression profile to that of the control transplant population (CD44hi $\left.\mathrm{CD} 45 \mathrm{RB}{ }^{\text {hi }} \mathrm{CD} 62 \mathrm{~L}^{\text {int }}\right)$, suggesting divergence of 2 distinct $T$ cell populations within the same host - the $\mathrm{T}_{\mathrm{EM}} \mathrm{CD}^{+}{ }^{+}$Ultimer $^{+}$versus the effector CD $4^{+}$Ultimer $^{-}-$independent of effects of transplantation.

Given the spontaneous $\mathrm{T}_{\mathrm{EM}}$ status of $\mathrm{CD}^{+}{ }^{+} \mathrm{Ultimer}^{+}$cells, we then addressed whether or not $\mathrm{T}$ cells from LV-TCR transplants would immediately react to Tyrp1-specific targets. To test this, splenocytes from 6-month-old LV-TCR and control transplants were harvested, then stimulated ex vivo for 24 hours with peptide or tumor. As shown Figure 8C, cells obtained from the LV-TCR group responded to Tyrp1-specific targets, secreting IFN- $\gamma$ only (but not IL-4 or IL-17A; data not shown), in response to Tyrp $1_{277-297}$ at titering peptide concentrations and to B16-DR4, but not to control targets $\mathrm{HA}_{306-318}$ or to control tumor MC38DR4. Control transplants were completely unresponsive to all Tyrp1-specific targets (data not shown). These results appear consistent with specific and high-avidity (recognition observed at $1 \mathrm{nM}) \mathrm{Th}_{1}$-polarized $\mathrm{T}$ cell population.
$C D 4^{+} T$ cells from secondary transplants exhibit ongoing gene-specific TCR stability and multi-copy integration of the LV gene product. Secondary transplants were prepared to further demonstrate stability of TCR gene expression. Chimeric unfractionated BM was obtained from three 12-month-old primary transplants (per experiment), as shown in Figure 2, and injected without addition of competitive BM into lethally irradiated DR4 Tg mice (5 mice per experimental group). Six months after secondary transplantation, TCR-specific cells were identified at a level of $7.1 \% \pm 4.5 \%$ within the total cellular compartment $\left(\mathrm{CD} 45^{+}\right.$Ultimer $\left.^{+}\right), 47.5 \% \pm 8.3 \%$ within the global CD3 compartment $\left(\mathrm{CD}^{+} 5^{+} \mathrm{CD}^{+}{ }^{+}\right.$Ultimer $\left.^{+}\right)$, and $53.1 \% \pm 10.7 \%$ within the CD4 subcompartment $\left(\mathrm{CD} 45^{+} \mathrm{CD}^{+}{ }^{+} \mathrm{CD} 4^{+}\right.$Ultimer $\left.^{+}\right)$(see Figure 9, A and B). These results were notable for higher expression levels compared with the 12 -month expression levels observed in the parental primary transplant group (12-month primary CD4 vs. 6-month secondary CD4; $P=0.02)$. Again, high-level co-expression (93\%) of the endogenous murine TCR $\beta$ was observed in the $\mathrm{CD}^{+}{ }^{+} \mathrm{Ultimer}^{+}$subpopulation.

Having demonstrated stable and high-level TCR gene expression 18 months after a primary transplantation, we evaluated genetic stability of 6-month-old secondary transplant recipients. Genomic 


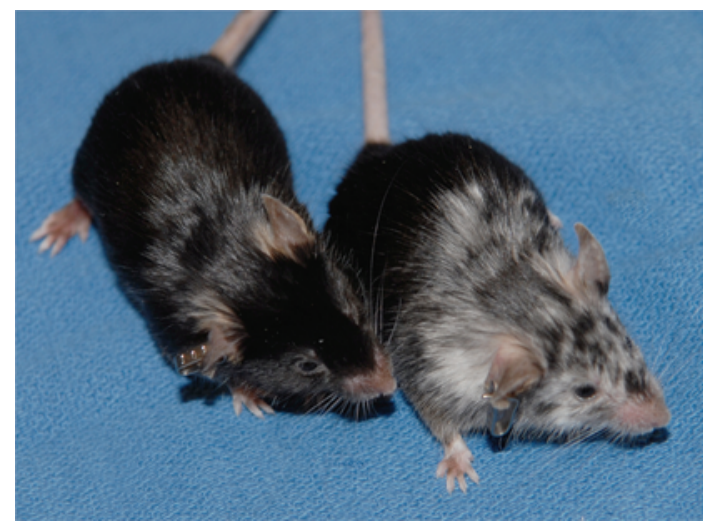

\section{Figure 6}

LV-TCR transplant recipients develop spontaneous autoimmune vitiligo. DR4 Tg mice transplanted with LV-TCR-transduced HPCs (right mouse) developed autoimmune vitiligo at 10 weeks, but the control transplants (left mouse) did not.

DNA (gDNA) was prepared from $1 \times 10^{5} \mathrm{BM}$ cells (from TCR Tg, LV-TCR, and control transplants) and analyzed by quantitative PCR (qPCR) to determine relative TCR gene expression and by standard PCR to determine the number of LV integrants. Using a probe specific for the variable chain of the humanized $\alpha$ subunit, relative TCR gene expression was determined by qPCR from LV-TCR, TCR $\mathrm{Tg}$, and control transplants against a standard curve generated from plasmid LV-TCR DNA. As shown in Figure 9C, LV-TCR gene expression was 1,000 -fold greater than the background signal produced in control transplants but 43-fold less than that observed in the TCR-Tg group ( $P=0.01$ for LV-TCR vs. TCR-Tg). These results were consistent with differences in protein level TCR expression. Using a probe specific for the LV vector backbone, 4-6 integration sites and internal control fragment were identified by nested PCR in 3 separate LV-TCR transplant samples, compared with control transplant (0 integrants) (see Figure 9D). Both results demonstrate long-term post-transplant genetic stability and integration.

Secondary TCR transplant recipients reject subcutaneous melanoma. Immune reconstitution after BM transplantation (39), dendritic cell vaccination (40), or adoptive transfer of antigen-specific lymphocytes (41) enhances antitumor immune responses. Given high-level TCR gene expression, spontaneous autoimmunity, $\mathrm{T}_{\mathrm{EM}}$ activation, and in vitro antitumor activity, we asked whether long-term secondary transplant recipients would induce protective tumor immunity. To address this question, transplant recipients (both LV-TCR and control, 5 mice per group) were subcutaneously injected with B16-DR4 tumor cells. Because of the preexisting "activated" $\mathrm{T}_{\mathrm{EM}}$ status of transplanted animals, no additional cytokines, immune modulators (such as $\alpha$-CTLA-4),

\section{Table 1}

Txp, transplant. or vaccinations were added to enhance the antitumor effect. Beginning 3 days after injection, and every 3 days thereafter, the product of the perpendicular tumor diameters was recorded. As shown in Figure 10A, secondary LV-TCR transplant recipients significantly rejected tumor growth compared with control transplants over a 20-day period. In addition, tumor size between day 12 and day 20 in the LV-TCR group was not significant $(P=0.09)$, suggesting cessation of tumor growth. Based on IHC staining of paraffin-embedded specimens, tumors from LV-TCR transplants but not controls were characterized by extensive necrosis and hemorrhagic infiltrates (Figure 10, B and C; H\&E staining). Tumors from LV-TCR transplants were also found to contain dense trafficking populations of $\mathrm{CD}^{+}$and human TCR- $\beta^{+}$(gene-specific) tumor-infiltrating lymphocytes (Figure 10, C-E). A similar infiltrative pattern was observed in the autoreactive vitiligo skin specimens.

LV-TCR gene-modified human HSCs repopulate 6-month-old NS2 transplant recipients and develop into TCR gene-specific CD4 $4^{+} T$ cells. Having now established herein an animal model of gene-modified HSC transplantation, as well as having previously shown that transduced mature human lymphocytes can specifically recognize tumor targets, we next sought to determine whether human HSCs would engraft and develop into TCR gene-specific CD4 $4^{+} \mathrm{T}$ cells. NOD-SCID-IL2 $r \gamma^{\text {null }}$ (NS2) mice have emerged as a reliable vehicle of human $\mathrm{T}$ cell development following transfer of either HSCs or progenitor $\mathrm{T}$ cell populations (42). To address this question, $\mathrm{CD} 34^{+} \mathrm{CD} 38^{-}$cells were purified from cord blood of 5 separate donors. Following in vitro prestimulation, LV-TCR-transduced $\mathrm{CD} 34^{+} \mathrm{CD} 38^{-}$cells were transplanted into sublethally irradiated NS2 mice (5-6 per experiment). To ensure co-expression of HLADR4, animals were competitively reconstituted with BM from DR4 Tg mice. Six months after transplantation, splenocytes were column enriched for human CD45 expression, then stained with antibodies to human CD3, CD4, and CD8 and the Tyrp1 Ultimer, and analyzed by flow cytometry. As shown in Figure 11, A and B, although human $\mathrm{CD}_{4} 5^{+}$cells represented only $10 \%$ of all mononuclear cells, human $\mathrm{CD}^{+} \mathrm{T}$ cells were largely $\mathrm{CD}^{+}$(45\% human $\mathrm{CD}^{+} / \mathrm{SP} \mathrm{CD}^{+}$vs. $4 \%$ human $\left.\mathrm{CD}^{+} / \mathrm{SP} \mathrm{CD}^{+}\right)$. A subpopulation of $\mathrm{DP}\left(49 \% \mathrm{CD}^{+} \mathrm{CD}^{+} \mathrm{CD}^{+}\right)$cells also appeared to have developed, suggesting that NS2 mice may fail in this experimental setting to fully differentiate all T cells. Most importantly, TCR-specific levels were equally well expressed within all $\mathrm{T}$ cell populations, suggesting autonomous TCR gene expression regardless of phenotype.

Summary of vitiligo development displayed as total numbers of mice in various transplanted combinations in endogenous or nontransplanted strains

$\begin{array}{lccccc}\text { Primary HSC } & \text { Competitor BM } & \text { Txp host } & \begin{array}{c}\text { Developed } \\ \text { vitiligo? }\end{array} & \text { Age of onset } & \begin{array}{c}\text { Mice with vitiligo/ } \\ \text { total number of mice }\end{array} \\ \text { Txp LV-GFP } & \text { DR4 TG } & \text { DR4 TG } & \text { No } & \text { N/A } & 0 / 15 \\ \text { Txp LV-TCR } & \text { DR4 TG } & \text { DR4 TG } & \text { Yes } & 8-16 \text { weeks } & 19 / 23 \\ \text { Txp LV-TCR } & \text { DR4 TG } & \text { C57BL/6 } & \text { Yes } & 8-16 \text { weeks } & 9 / 11 \\ \text { Txp LV-TCR } & \text { C57BL/6 } & \text { C57BL/6 } & \text { No } & \text { N/A } & 0 / 8 \\ \text { Txp TCR TG } & \text { DR4 TG } & \text { DR4 TG } & \text { Yes } & 6-10 \text { weeks } & 17 / 25 \\ \text { Txp TCR TG } & \text { DR4 TG } & \text { C57BL/6 } & \text { Yes } & 6-10 \text { weeks } & 9 / 12 \\ \text { Txp TCR TG } & \text { C57BL/6 } & \text { C57BL/6 } & \text { No } & \text { N/A } & \text { N/6 } \\ \text { Non-Txp TCR+DR4+ } & \text { N/A } & \text { N/A } & \text { No } & \text { N/A } & \text { N/A } \\ \text { Non-Txp TCR+DR4- } & \text { N/A } & \text { N/A } & \text { No } & \text { N/A } & \text { N/A }\end{array}$


A

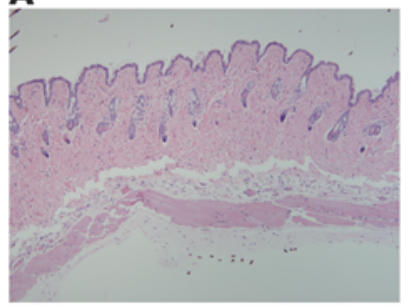

C

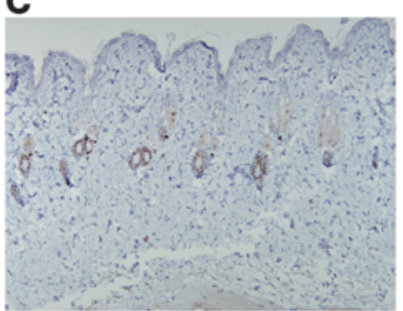

$\mathbf{E}$

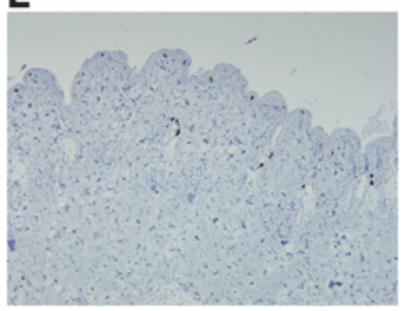

G

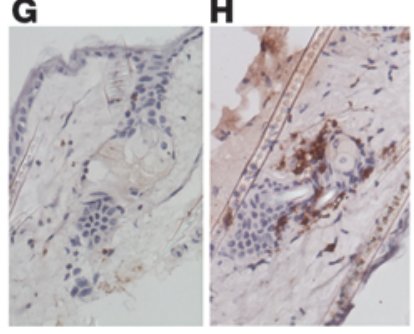

B

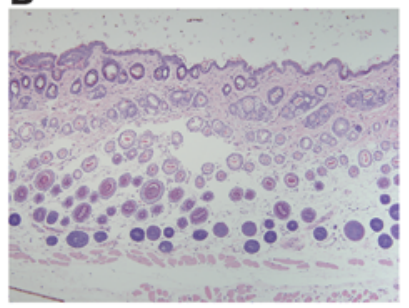

D

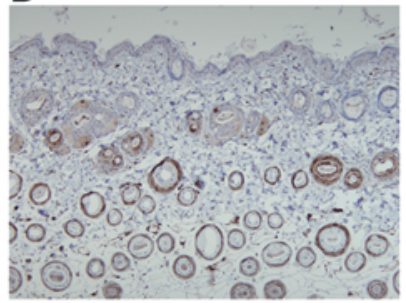

$\mathbf{F}$

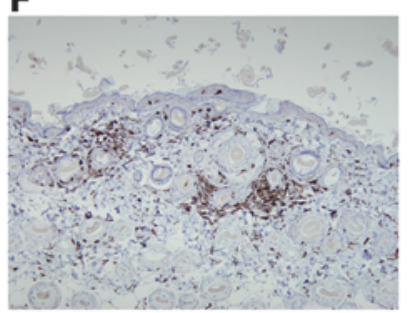

I

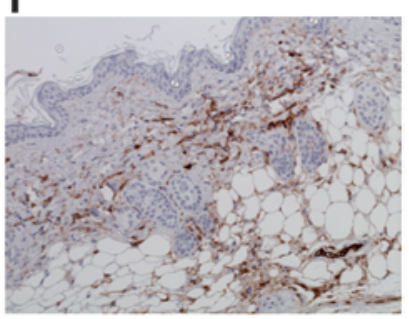

\section{Discussion}

While most gene therapy strategies have focused on the introduction of defective genes or antigens or used fluorescent gene products to track long-term development, few have introduced TCR genes into HSCs (18). In those examples that do exist, TCR genes introduced with retroviral vectors targeted only experimental antigens (OVA) $(43,44)$. Herein, we report a new translational model of TCR-based immunotherapy with potential direct applicability to patients with metastatic melanoma. We demonstrate spontaneous autoimmunity and destruction of subcutaneous melanoma that occur following long-term transplantation with gene-modified HSCs. Our results, based on use of a high-expression LV system to deliver to HSCs a potent class II-restricted CD4+ TCR, were not assisted by use of vaccines, cytokines, or immune modulators to either induce a population of autoreactive memory $\mathrm{T}$ cells or achieve antitumor effects.

To design a model encompassing features that would address both self-tolerance and tumor immunity while also serving as a potential source of preclinical information, we utilized a previously identified tumor-reactive, self-reactive, Tyrp1-specific, DR4restricted $\mathrm{T}$ cell clone (19). We then engineered both a high-expression LV and a TCR Tg mouse expressing the same TCR genes. We focused on current generation SIN lentivectors not only because of

\section{Figure 7}

Vitiligo is associated with gross distortion of the natural skin architecture, melanocyte destruction, and TCR gene-specific CD4+ $\mathrm{T}$ cell infiltration. (A-I) IHC analysis of paraffin-embedded and frozen skin sections from control and LV-TCR transplants 6 months after transplantation. (A and B) H\&E staining (original magnification, $\times 100),(\mathbf{C}$ and D) S-100 staining (original magnification, $\times 200$ ), (E and F) CD3 staining (original magnification, $\times 200),(\mathbf{G}$ and $\mathbf{H})$ CD8 versus CD4 staining on frozen sections of LV-TCR only (original magnification, $\times 400$ ), and (I) human TCR $\beta$ staining of LV-TCR only (original magnification, $\times 200$ ). IHC was performed on more than 4 independent sample groups with equivalent results.

their enhanced capacity to stably transduce metabolically dormant HSCs, but because of their improved biosafety profile compared with standard $\gamma$ retroviruses (45). Although a case of clonal dominance has been reported to the NIH (but not formally published) following use of a $\beta$-globulin $\mathrm{LV}$, overall evidence suggests that lentivectors have lower rates of genotoxicity and an altogether safer integration profile when compared with $\gamma$ retroviruses (46). These experimental observations have been further supported by clinical trials either ongoing or in preparation for treatment of patients with HIV, $\beta$-thalassemia, Parkinson disease, adrenoleukodystrophy, and Wiskott-Aldrich syndrome (47).

Following creation of a dual-functional LV-TCR and TCR Tg model, we demonstrated engraftment, thymic trafficking and differentiation, specific $\mathrm{CD}^{+} \mathrm{T}$ cell selection, long-term TCR gene expression in both murine and humanized transplants, genomic LV integration, spontaneous post-transplant autoimmunity, and hemorrhagic necrosis of subcutaneous melanoma. We also discovered that despite integration of LV-TCR into HSCs, endogenous mouse TCR expression was still fully intact and co-expressed with our transgene. These new findings were based on staining with antibodies specific for murine $\mathrm{CD} 3$, an antibody specific for murine TCR $\beta$ chain, and the pentamer specific for the combined human TCR chains. These results indicated that co-expression likely results from 2 distinct autonomous sources of TCR gene expression: native TCR genes under the control of endogenous TCR promoter/enhancer elements and LV-TCR genes under control of the heterologous CMV promoter. There also appeared to be little evidence that any significant chain mispairing occurred. We conjecture that human TCR genes were coexpressed in mouse $T$ cells, creating a species-specific human-mouse TCR chain dichotomy, thus minimizing the risk of mixed TCR-dimer formation. Such a hypothesis is supported by results from studies that have introduced murine TCR genes specific for p53 into human $\mathrm{T}$ cells (48) or following genetic modification of TCR chains (49).

Given the importance of early effector phenotypes, we designed an experimental translational model focused on long-term expression of unmanipulated $\mathrm{CD} 4^{+} \mathrm{T}$ cells. A permanently reconfigured immune system of durable high-frequency lymphocytes has long been a goal of immunologists and clinicians in pursuit of treatments for viral pathogens and cancer (50). Concerns persist, however, regarding the feasibility of delivering such a treatment within a sufficiently narrow time frame. Most clinical therapies and translational models have focused on fully actualized treatments that deliver their effect with little delay, such as vaccines (peptides, viruses, dendritic cells, heat shock proteins, gene-modified tumor cells), cytokine infusions (IL-2, IL-7, IL-12, GM-CSF), immune modulators (Treg depletion, anti-CTLA-4), or adoptive immunotherapies (tumor-infiltrating lymphocytes, cloned T cells, 
A
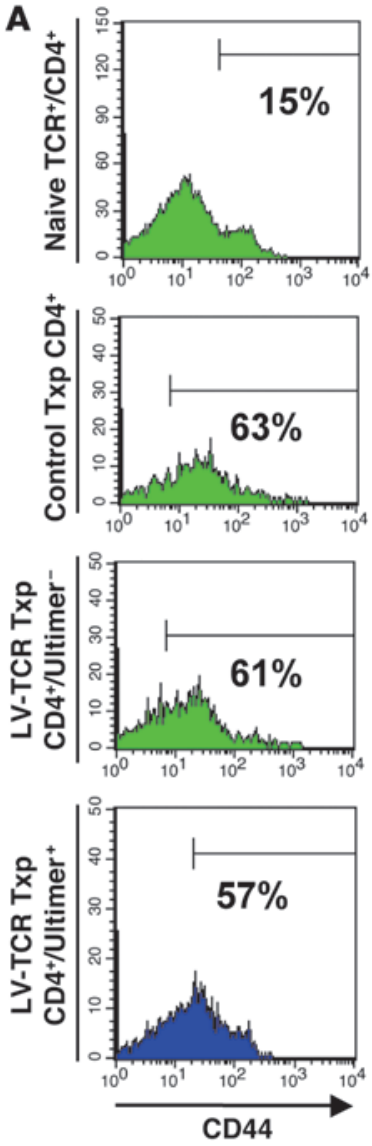

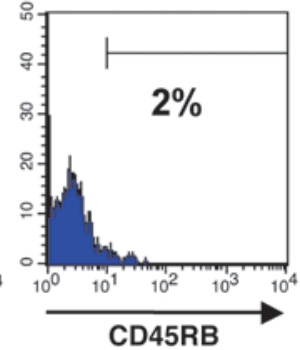

CD45RB
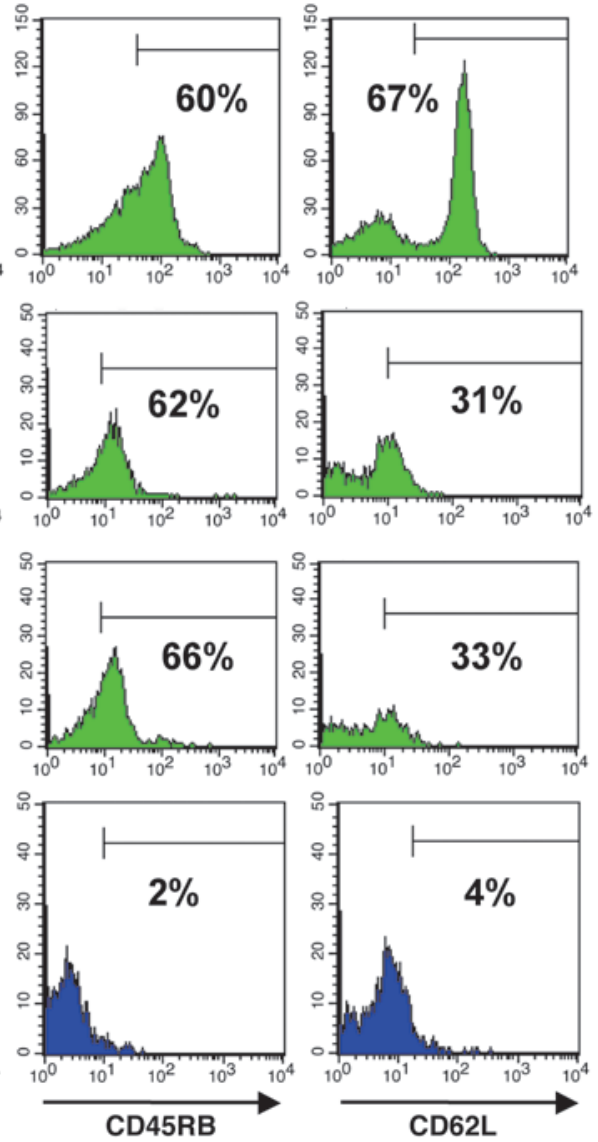

B
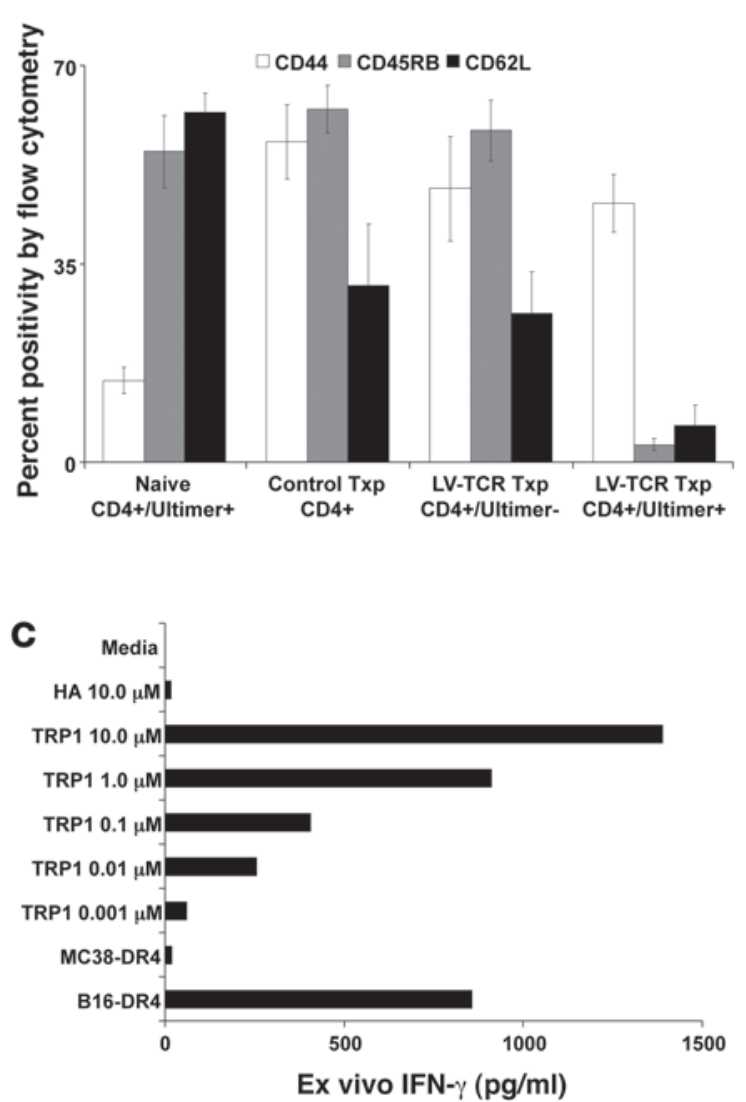

Figure 8

Transplant recipients exhibit a $T_{E M}$ phenotype and react spontaneously to tumor ex vivo. (A) PB samples at 6 months post-transplantation were obtained and stained with antibodies against CD4, Tyrp1 Ultimer, CD44, CD45RB, and CD62L. LV-TCR transplant CD4+Ultimer+ cells exhibited a $\mathrm{T}_{\mathrm{EM}}$ phenotype $\left(\mathrm{CD} 45 \mathrm{RB}^{\circ}{ }^{\circ} \mathrm{CD} 62 \mathrm{~L}^{\mathrm{l}}{ }^{\circ} \mathrm{CD} 44^{\mathrm{hi}}\right)$, while the polyclonal $\mathrm{CD} 4+$ Ultimer and $\mathrm{CD} 4{ }^{+}$control population exhibited a more generalized effector

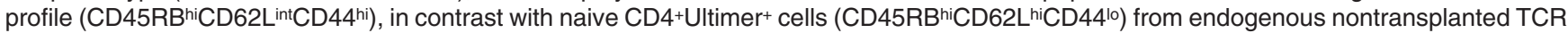
Tg. (B) Summary of activation status of all CD4+ subpopulations. (C) Gene-modified T cells exhibited a Th, -polarized cytokine profile in response to specific peptide and tumor. Splenocytes from 6-month-old LV-TCR and LV-GFP transplants were stimulated ex vivo for 24 hours with peptide (Tyrp1 $1_{277-297}$ or $\mathrm{HA}_{306-318}$ ) or tumor (MC38-DR4 or B16-DR4). Cytokine release (IFN- $\gamma$ ) was measured by ELISA. Data (mean \pm SEM; $n=5$ per group) and flow cytometry are representative of 3 independent experiments.

gene-modified T cells) $(51,52)$. Limitations and delays in immune reconstitution are a well-described physiologic consequence of autologous HSC transfer, and kinetics of individual mononuclear populations favor early return of granulocytes and B cells, with $\mathrm{CD}^{+} \mathrm{T}$ cells often being the last population to return to normal levels (53). In our model, gene-specific $\mathrm{CD} 4^{+} \mathrm{T}$ cells reached their peak expression after 4-6 months, suggesting a similar problem of transplant $\mathrm{T}$ cell recovery. To improve T cell output, IL-7 administration has been successfully used in patients with cancer (54). Nevertheless, the Achilles heal of such a potential treatment in patients pertains to the relatively late emergence of $\mathrm{CD}^{+} \mathrm{T}$ cells.

Despite these delays, timing of maximum (or even normal) $\mathrm{T}$ cell recovery may, ironically, not be the most meaningful physiologic endpoint of gene-modified HSC transfer. Although gene-specific $\mathrm{T}$ cells peaked 4-6 months after transplantation, low levels were detected after 8 weeks and were found temporally correlated with vitiligo development (occurring between 8 and 12 weeks). These findings suggest that the final magnitude or frequency of the TCR-specific population was less meaningful than their qualita- tive behavior or the amplitude (rate of expansion over time) of their emergence into the periphery. Such observations have been supported by other models, in which small numbers of $\mathrm{T}$ cell clones differing only by activation status or $\mathrm{T}$ helper phenotype more effectively induce autoimmunity when compared with control populations $(5,6,8,23)$. Is an 8 - to 12 -week wait too long for patients with metastatic melanoma? Could other treatments, including use of BRAF inhibitors, adoptive transfer of tumor reactive $\mathrm{T}$ cells, anti-CTLA-4 therapy, or IL-7 administration be used to bridge the gap, as TCR levels increase and become therapeutic? These issues would clearly need to be addressed in any proposed clinical trial.

In our model, vitiligo developed not only in DR4 Tg mice but also in C57BL/ 6 transplant recipients. These observations were associated with corresponding similar levels of TCR-specific cells (data not shown). It is well known that melanocytes isolated from normal C57BL/6 mice have low class II expression (55). Vitiligo development in $\mathrm{C} 57 \mathrm{BL} / 6$ recipients underscores a broader range of effects by gene-specific $\mathrm{CD}^{+} \mathrm{T}$ cells, regardless of their relative magnitude or frequency or the presence of Tregs (13). Polarized 

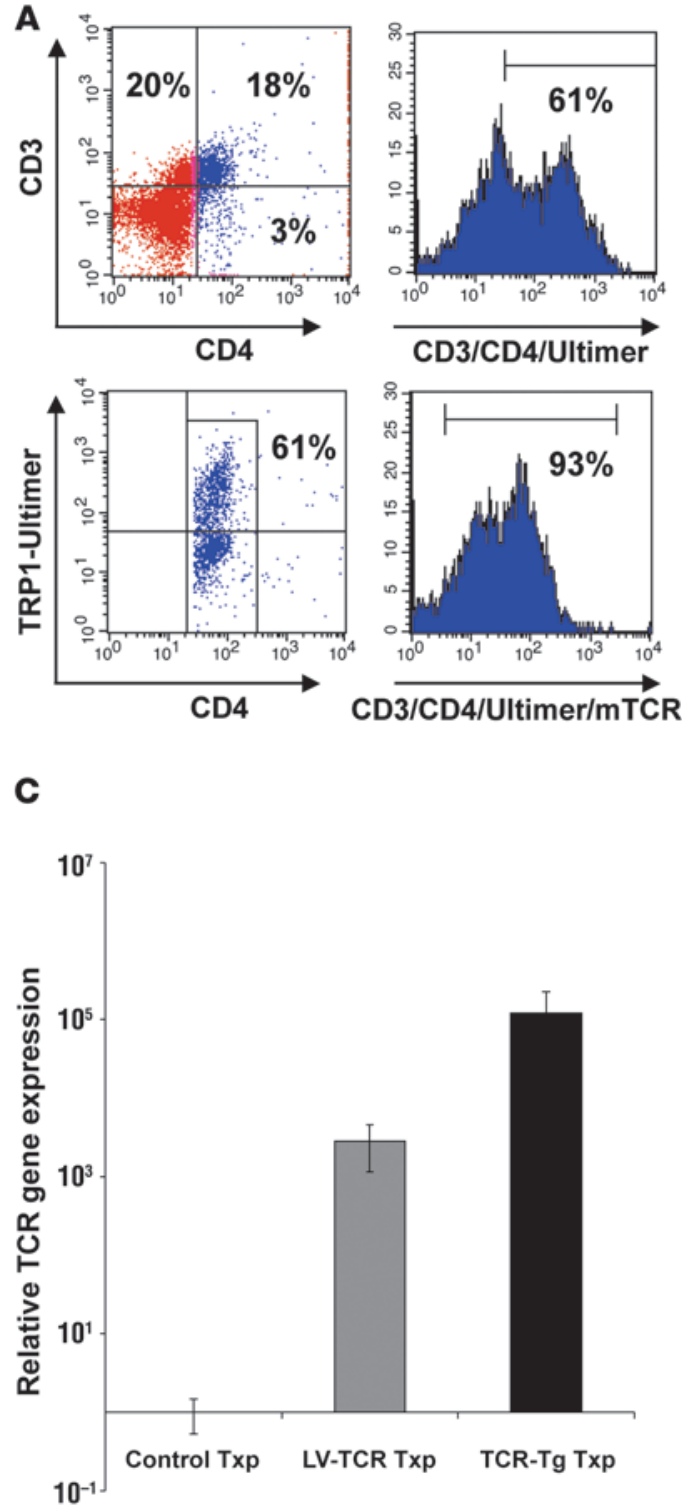
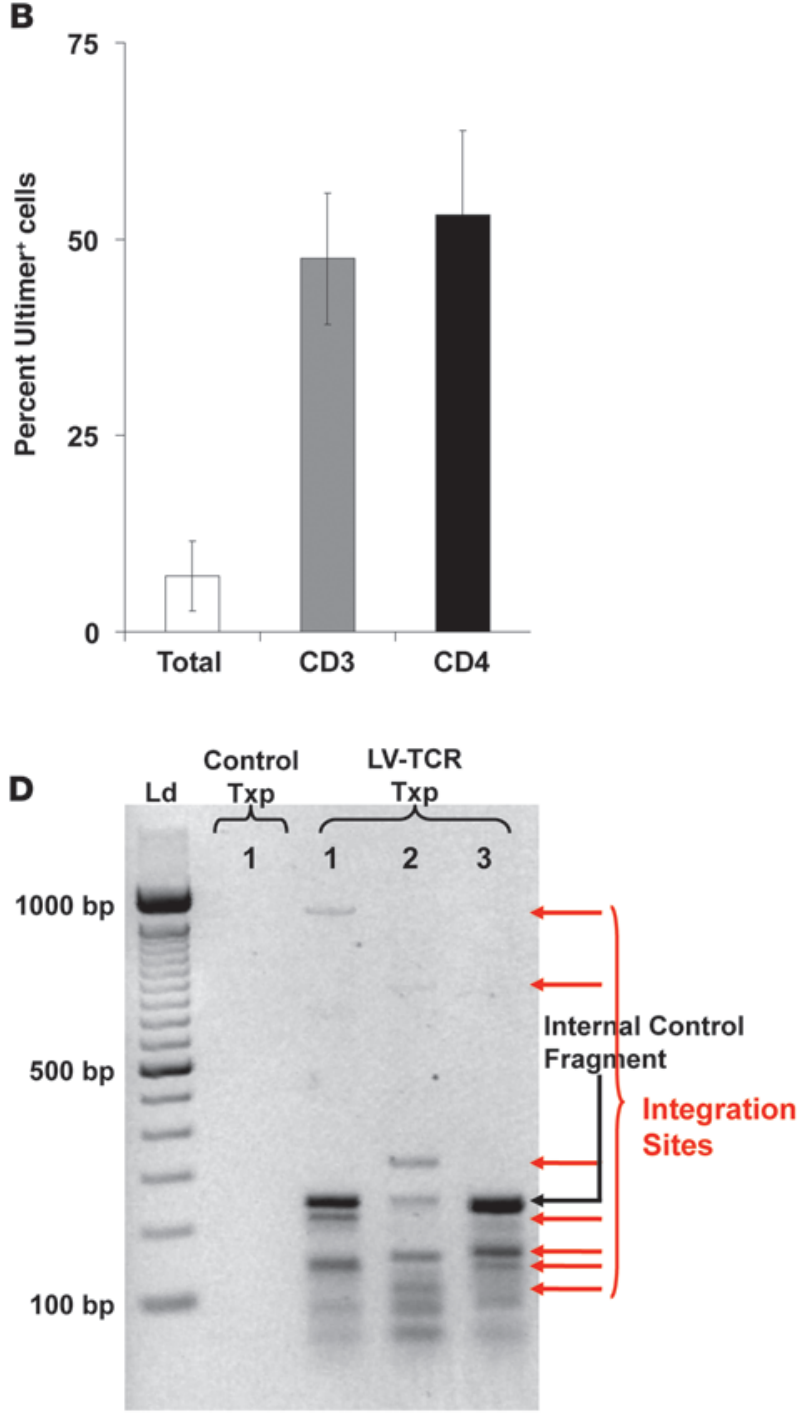

\section{Figure 9}

CD4+ $\mathrm{T}$ cells from secondary transplant recipients exhibit high-level gene TCR expression and multi-copy integration of the LV-TCR gene product. PB from 6-month secondary transplants were stained with antibodies against CD4, CD8, CD3, and Tyrp1 Ultimer and analyzed by flow cytometry. (A) TCR-specific CD4+ T cells were identified at a level of $61 \%$ within the CD4 subcompartment (CD3+CD4+Ultimer $\left.{ }^{+}\right)$. Co-expression (93\%) of endogenous murine TCR $\beta$ was also observed in the CD4+Ultimer+ subpopulation. (B) Summary of 6-month TCR gene expression within secondary transplant. Total, CD3, and CD4 populations: $7.1 \% \pm 4.5 \%$ within the total cellular compartment $\left(\mathrm{CD} 45^{+} \mathrm{Ultimer}\right), 47.5 \% \pm 8.3 \%$ within the global CD3 compartment (CD45+CD3+Ultimer+), and $53.1 \% \pm 10.7 \%$ within the CD4 subcompartment $\left(\right.$ CD $455^{+}$CD3 ${ }^{+}$CD $4+{ }^{+}$Ultimer+). $(C)$ Relative TCR gene expression was more than 1,000-fold greater than control transplants but 43-fold less than TCR Tg transplant $(P=0.01)$. gDNA was prepared from BM obtained from 6-month-old secondary LV-TCR and control transplants and 12-month-old primary TCR Tg transplants and analyzed by GPCR for relative TCR gene expression using an $\alpha$-chain-specific probe. Relative gene expression is displayed; error bars indicate the $95 \%$ confidence interval. (D) Multicopy integration of the LV-TCR gene product was found in secondary transplant recipients. Using a vector backbone-specific probe, 4-6 integration sites were identified in 3 separate LV-TCR transplant samples compared with control. Data (mean \pm SEM; $n=5$ per group) and flow cytometry are representative of 2 independent experiments.

$\mathrm{Th}_{1}$ cell production of IFN- $\gamma$ has been shown to produce multiple effects, including direct melanocyte cytotoxicity, upregulation of MHC molecules that enhance target recognition, and enhancement of APC activation, leading to further amplification of T helper response (9). Such functions have been associated with the unique but underutilized properties of $\mathrm{CD} 4^{+} \mathrm{T}$ cells.
While long-term cellular persistence was an initial objective of this model, the amplitude of gene-specific $\mathrm{T}$ cell expansion (between 8 and 24 weeks) and $\mathrm{T}_{\mathrm{EM}}$ activation were dramatic and, we propose, associated with both autoimmunity and antitumor activity. Both spontaneous and homeostatic proliferation (HP) represent naturally occurring multi-log expansion of lymphocytes in 


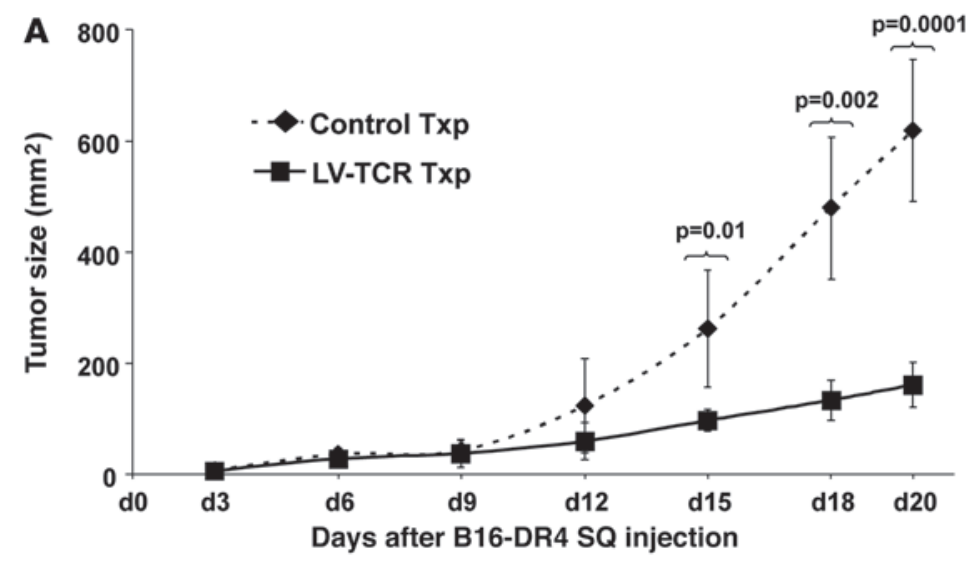

B

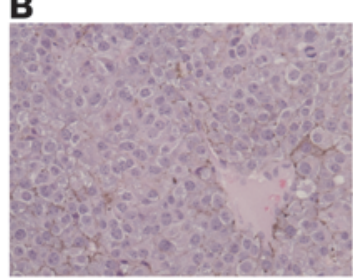

D

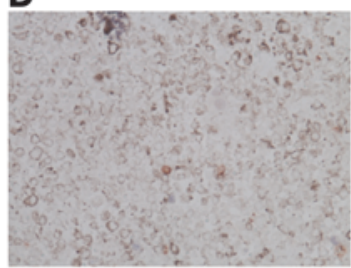

C

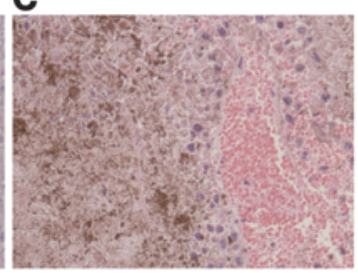

E

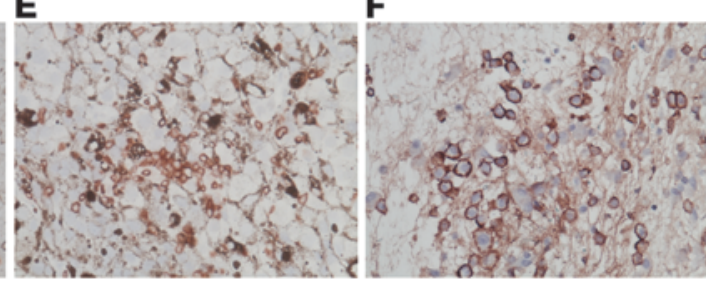

\section{Figure 10}

Six-month secondary TCR transplant recipients reject subcutaneous melanoma. (A) LV-TCR and control transplants (5 mice per group) were subcutaneously injected with $5 \times 10^{5}$ B16-DR4 tumor cells. Three days after injection, tumor size was recorded. Statistical significance between groups was based on tumor size. Data are displayed as mean \pm SEM with $P$ value; $n=5$ per group. Experiments were performed in a blinded, randomized fashion and executed independently 3 times. (B and $\mathbf{C}$ ) Tumors from LV-TCR transplants were necrotic. IHC staining of paraffin-embedded tumor (control and LV-TCR) specimens: H\&E staining; original magnification, $\times 400$. (D-F) Tumors from LV-TCR transplants were associated with a dense TCR gene-specific infiltration: CD3 and human TCR- $\beta$ staining; original magnification, $\times 400$. NovaRED substrate was used instead of DAB (previously used on skin) to more effectively differentiate between necrotic tumor/pigment and cellular infiltrate. IHC was performed on 3 independent samples per group with similar results. response to depletion or ablation, followed by either BM reconstitution or adoptive transfer $(56,57)$. Immune responses that occur in response to both forms of proliferation favor the precipitation of autoimmune events (58). These observations have been associated with a number of factors, including increased availability of homeostatic cytokines (IL-7, IL-15, IL-21), depletion or inhibition or Tregs, generalized host inflammation, and availability of selfligands $(56,59,60)$. IL-7 availability, in particular, has been found to be a critical factor in $\mathrm{T}$ helper and thymocyte survival along with promoting HP of both naive and memory T cells (61).

There are a number of possible explanations for the proliferative response of TCR-specific CD4 ${ }^{+} \mathrm{T}$ cells. Even though the importance of IL-7 has been clearly stated, we found IL-7 receptor expression by flow cytometry (data not shown) on thymic DPs and SP CD4 cells as well as $\mathrm{PB}$ and splenic $\mathrm{CD} 4^{+} \mathrm{T}$ cells to be statistically no different between the Ultimer ${ }^{+}$and Ultimer- populations. On the other hand, although generalized antigen may be limiting to the vast majority of T cells, Tyrp1-loaded dendritic cells may be uniquely available to the high-avidity $\mathrm{CD}^{+}{ }^{+}$Ultimer $^{+}$cell population. Unlike most antigens, a fragment of the Tyrp1 protein (the highest expressed of all melanocyte differentiation antigens) containing the 277-297 epitope is secreted into the peripheral circulation (62). In theory, circulating Tyrp1 could be captured by immature APCs (either in the skin or within peripheral lymphoid organs) that in turn become activated during systemic injury from lethal irradiation (63). Expansion of $\mathrm{CD}^{+} \mathrm{T}$ cells has been tied not only to the relative load of antigen, but to the prolongation of that antigen load well after initial exposure $(64,65)$. Moreover, proliferative responses have been found more strongly linked to the strength of secondary TCR signaling than to relative availability of IL-7 (38). With this said, the magnitude of the burst size may be a simple function of mass effect, given the high frequency of gene-modified HSCs and T cell progenitors introduced at the time of primary transplantation.

Other explanations may also account for both magnitude of burst size and unique $\mathrm{T}_{\mathrm{EM}}$ status of CD4 $4^{+} \mathrm{Ultimer}^{+}$cells. In general, 2 competing models of memory $\mathrm{T}$ cell development have been proposed. The first involves separate lineage from effectors, and the second proposes that $T$ cells initially pass through an effector stage $(66,67)$. As a consequence of either scenario, $T$ cell clones can give rise to multiple effector and memory $T$ cell populations by means of asymmetric cell division $(38,68)$. After antigen exposure, memory cell expansion is classically followed by contraction and stable persistence (69). Although we showed activation status at 6 months following primary transplantation (similar profiles were found at all time points), we found a sharp increase in total CD4 ${ }^{+}$Ultimer $^{+} \mathrm{T}$ cells between 12-month primary and 6-month secondary transplants, consistent with both memory decay and re-expansion. We also found a splitting of 2 distinct $T$ cell populations within the same host irrespective of the effects of transplantation. $\mathrm{CD}^{+}{ }^{+}$ltimer $^{+} \mathrm{T}$ cells may have had both a competitive survival advantage and propensity for memory differentiation based on the relatively high availability of Tyrp1 and a corresponding high-frequency, high-affinity cognate TCR (57).

The most clinically significant evidence we present is the near total liquefaction of tumor following subcutaneous implantation in long-term secondary transplants. These results demonstrate not only potent antitumor activity 18 months after initial transplanta- 

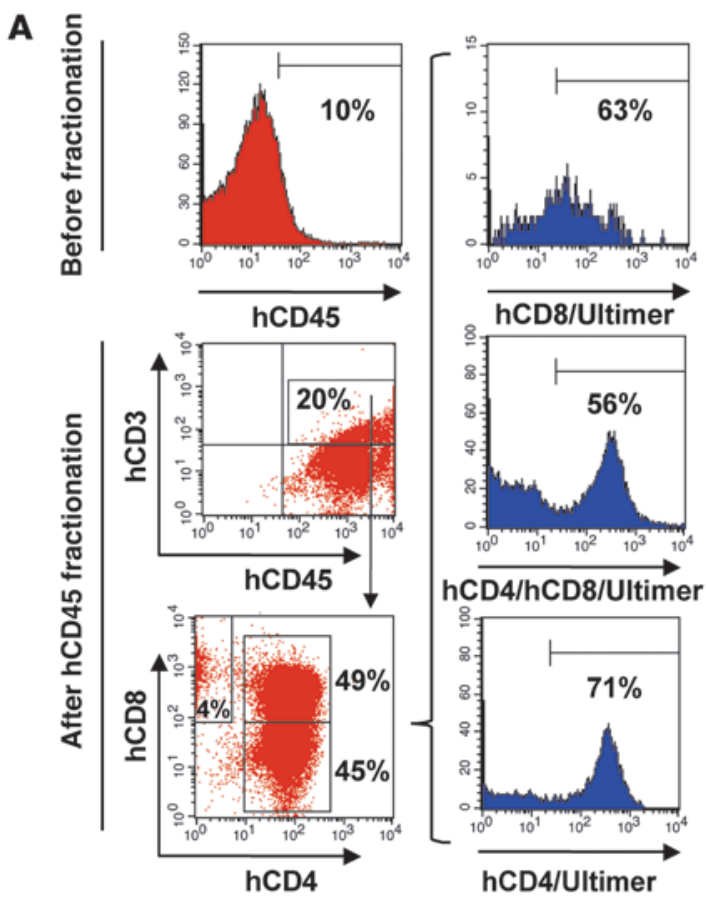

\section{Figure 11}

LV-TCR gene-modified human CD34+CD38- HPCs obtained from cord blood functionally engraft and repopulate 6-month-old NOD-SCID-IL2rynull (NS2) transplant recipients. (A) Flow cytometry analysis of splenocytes 6 months after transplantation demonstrated human CD45 expression (10\%) as a function of all gated mononuclear cells (mouse and human; pre-fractionation sample) and post-fractionation expression of human CD45 and CD3. Human CD45/CD3/CD4 versus human CD45/CD3/CD8 expression demonstrated skewing toward CD4+ $T$ cell differentiation ( $45 \%$ human $\mathrm{CD} 3^{+} / \mathrm{SP}$ CD $4+$ versus $4 \%$ human $\mathrm{CD} 3^{+} / \mathrm{SP}$ $\mathrm{CD}^{+}$versus $49 \%$ DP human $\left.\mathrm{CD} 3^{+} \mathrm{CD} 4^{+} \mathrm{CD} 8^{+}\right)$. TCR gene levels were well expressed in all T cell subpopulations. (B) Six-month transplant summary of TCR gene expression within human SP CD8 $8^{+}(55 \% \pm 10 \%)$, SP CD $4+(63 \% \pm 15 \%)$ and DP $(51 \% \pm 11 \% ; P=$ NS) T cell subpopulations. Data (mean \pm SEM; $n=5$ per experiment) and flow cytometry are representative of 3 independent experiments.

tion, but also dense cellular trafficking of LV-TCR-specific T cells. While many adoptive immunotherapies have either maximized their therapeutic effect or been totally dependent upon cytokine administration, vaccination, myelodepletion (lethal irradiation or RAG knockouts), or use of immune modulators ( $\alpha$-CTLA- 4$)(23$, $70,71)$, we achieved this effect without such assistance. We propose that these freestanding antitumor effects were likely secondary to both post-transplant proliferation and spontaneous $\mathrm{T}_{\mathrm{EM}}$ activation of TCR-specific cells. In conclusion, we suggest that this translational model of immunotherapy, utilizing unique properties of HSC transplantation, LV technology, and $\mathrm{CD}^{+} \mathrm{T}$ cells, has potential for novel treatment of patients with metastatic melanoma.

\section{Methods}

Animals and cell lines. Murine class II-deficient, DR4-IE transgenic (DR4 $\mathrm{Tg}$ ) mice fully backcrossed onto a C57BL/6 background were purchased from Taconic Farms. B6.SJL-Ptprca Pepc ${ }^{\mathrm{b}} /$ BoyJ (or Boy-J) and NOD/SCID/ IL2r $\gamma^{\text {null }}$ (NS2) mice were purchased from The Jackson Laboratory. We developed a new TCR Tg mouse strain described below. All mice were 6-10 weeks old for experiments and were housed and bred at the Indiana University Laboratory Animal Research Center barrier facility under an established animal protocol. Murine tumor lines B16 (ATCC) and MC-38 (ATCC), trations) or tumor lysates (at $10^{6}$ cell equivalents $/ \mathrm{ml}$ ). To upregulate MHC class II, $624 \mathrm{Mel}$ was pretreated with IFN- $\gamma$ for 48 hours at $200 \mathrm{U} / \mathrm{ml}$. All targets $\left(10^{5}\right)$ and $\mathrm{T}$ cells $\left(10^{5}\right)$ were cocultured in duplicates in U-bottom 96-well plates for 24 hours. Culture supernatants were assayed for IFN- $\gamma$ using commercially available ELISA kits (BD Biosciences). All assays were performed at least twice, with similar experimental results.

Cloning of TCR. We had previously identified a Tyrp1-specific, tumorreactive HLA-DR4-restricted $\mathrm{CD} 4{ }^{+} \mathrm{T}$ cell from a patient with metastatic melanoma (19). The established line was cloned by limiting dilution (73), then followed by the isolation and identification of full-length TCR $\alpha$ and $-\beta$ subunits, as previously described $(24,25)$. In short, total RNA was extracted from TD Clone-2, and each TCR subunit was amplified by a $5^{\prime}$ RACE method (GeneRacer Kit; Invitrogen). PCR products were TA cloned and sequenced to determine $V \alpha / V \beta$ usage. After determining specific $\alpha$ and $\beta$ chains, full-length amplification, TA cloning, and resequencing were performed on PCR products, yielding the following specific, fully amplified chains: TCR- $\alpha$ : V $\alpha 13-2 * 01$, J22*01; TCR- $\beta$ : V5.4*01, J1- $1 * 01$, D $1 * 01$. Specific VDJ regions were analyzed using the IMGT/V-QUEST search engine from the International Immunogenetics Information System (http://imgt. cines.fr/IMGT_vquest/vquest?livret=0\&Option=humanTcR).

Creation of TCR Tg. We developed a Tg mouse strain and named it "Tyrp1DR4-TCR Tg”' (TCR Tg). The $\alpha$ and $\beta$ genomic variable domains were PCR 
amplified from the same full-length sequence (described above) and TA cloned into pCR4TOPO (Invitrogen) validated by sequencing, subcloned into TCR cassette vectors provided by D. Mathis (Harvard Medical School, Boston, Massachusetts, USA; ref. 30), and co-injected into fertilized C57BL/6 embryos yielding $9 \mathrm{TCR} \mathrm{Tg}$ founder lines. Founder mice were screened by PCR for presence of transgene and then crossed with founder mice and with DR4 Tg mice to generate experimental colonies. Progeny were screened for allelic copies of TCR and DR 4 genes by PCR or by flow cytometry using PElabeled DR4 Ultimer containing the Tyrp $1_{277-297}$ epitope (ProImmune Ltd).

Construction of lentivectors. TCR $\alpha$ and $\beta$ chains were re-amplified with an optimal Kozak initiation sequence and restriction sites using PlatinumPfx polymerase (Invitrogen). To generate the IRES vector, the $\alpha$ chain was cloned into an IRES-containing derivative of PENTR1a (Invitrogen) from DraI to a SpeI site $5^{\prime}$ to IRES. The $\beta$ chain was cloned $3^{\prime}$ from an NcoI site at the 13th ATG of IRES to XbaI. Both chains were sequenced and LR-clonased into a modified Gateway (Invitrogen) destination LV plasmid (pRRLDest-Wsin) (74). These modifications included a CPPT (central polypurine tract derived from HIV-pol) sequence inserted between the REV response element (RRE), the CMV promoter, and the woodchuck hepatitis virus posttranslational regulatory element (WPRE) element proximal to the $3^{\prime}$ SIN-LTR (75). To generate the F2A vector, Furin-2A peptide sequence was exchanged through a series of intermediates for the IRES element, transferred into the pENTR plasmid, then LR-cloned from the pENTR plasmid into pRRL-Dest-Wsin. Similarly constructed vectors which contain GFP (LV-GFP) and DRA-IRES-DRB1*0401 (LV-DR4) were also prepared.

Preparation of $L V$ supernatant and determination of viral titer. LV-TCR-IRES and LV-TCR-F2A LV supernatants were prepared by transient transfection of $293 \mathrm{~T}$ cells in T-150 flasks with vector DNA $(26.4 \mu \mathrm{g})$, packaging plasmid pMDLgPRRE (containing the gag-pol accessory genes) $(13.2 \mu \mathrm{g})$, rev-expressing plasmid pRSV-rev $(6.6 \mu \mathrm{g})$, and envelope plasmid pMDGVSVG $(9.2 \mu \mathrm{g})$ using the ProFection Mammalian Transfection SystemCalcium Phosphate Kit (Promega). Culture medium was replaced 16-18 hours after transfection with OptiPro SFM (Invitrogen). Viral supernatants were harvested at 24 and 48 hours after media exchange, centrifuged at $2,000 \mathrm{~g}$, filtered through a $0.45-\mathrm{mm}$ cellulose acetate filter, and concentrated with a Centricon Plus-70 device (Millipore) at 2,000 $\mathrm{g}$ for $30 \mathrm{~min}$ utes. The concentrated viral supernatants were aliquoted and frozen at $-80^{\circ} \mathrm{C}$ before titer calculation. To determine the titer of frozen viral supernatants, SupT 1 cells were plated at $10^{5}$ cells/well in 6-well plates, exposed to serial dilutions $\left(10^{-2}, 10^{-3}, 10^{-4}\right)$ of concentrated vector supernatants in DMEM medium, and incubated for 4 hours in presence of polybrene at $8 \mu \mathrm{g} / \mathrm{ml}\left(5 \% \mathrm{CO}_{2}, 37^{\circ} \mathrm{C}\right)$. Cells were maintained in culture for 72 hours, stained with a PE-conjugated anti-human TCR $\beta$ chain antibody (BD Biosciences), and analyzed by flow cytometry. Titers were calculated using the following formula: titer $=(F \times C o / V) \times D$, where $F$ is the frequency of human TCR $\alpha / \beta$ chain (FITC; BD Bioscience) positive cells determined by flow cytometry, $C o$ is the total number of target cells infected, $V$ is the volume of the inoculum, and $D$ is the virus dilution factor.

Transduction protocol. Human PBMCs were transduced with either LV-TCR-IRES or LV-TRP1-F2A at titering MOIs after overnight prestimulation with IL-7 (29). Surface TCR expression and function were measured by flow cytometry 72 hours after transduction, using the Tyrp $1_{277-297}$-specific Ultimer (ProImmune), or were measured with a standard coculture and ELISA assay against targets. Transduction of murine HSCs was performed by first isolating BM from femurs and tibias of mice. Erythrocytes were removed from BM using ACK lysis buffer, and remaining cells were filtered through a $100-\mu \mathrm{m}$ filter and washed in PBS, $0.5 \%$ BSA, and 2 mM EDTA. Lineage depletion of BM was performed using a MACS lineage cell depletion kit (Miltenyi Biotec), yielding a purity of more than $95 \%$, a viability of more than $99 \%$, and with less than $0.1 \%$ staining for CD3 (data not shown).
Lin $^{-}$cells were maintained in StemPro SFM-24 medium (Invitrogen) supplemented with SCF $100 \mathrm{ng} / \mathrm{ml}$, TPO $10 \mathrm{ng} / \mathrm{ml}$, and Flt-3L $50 \mathrm{ng} / \mathrm{ml}$ and cultured overnight. Lin ${ }^{-}$cells were then harvested, counted, assessed for viability, and plated for transduction. Human CD $34^{+} / \mathrm{CD} 38^{-}$cells were isolated from cord blood as previously described (76) and similarly prestimulated. All transductions were performed in 24-well plates using a 500- $\mu 1$ reaction volume containing $1 \times 10^{5} \mathrm{CD} 34^{+} / \mathrm{CD} 38^{-}$cells, polybrene $8 \mu \mathrm{g} / \mathrm{ml}$, and concentrated lentivirus at an MOI of 15 . Transductions included a 2-hour $25^{\circ} \mathrm{C}$ spinoculation at $240 \mathrm{~g}$, followed by a 2 -hour $37^{\circ} \mathrm{C}$ incubation. Cells were incubated for an additional $12-24$ hours in cytokine media, then either analyzed by flow cytometry (after an additional 48 hours) or transplanted into recipient mice.

Transplantation protocol. Lin- cells were isolated and transduced with LV-TCR-F2A at an MOI of 15. A control transplant arm of similarly prestimulated Lin $^{-}$cells was also prepared. Competitive reconstitution was performed using Lin ${ }^{-}$cells $\left(\mathrm{CD} 45.1,5 \times 10^{4}\right)$ combined ( $\mathrm{LV}$ or control) with unfractionated $\mathrm{BM}\left(\mathrm{CD} 45.2,2.5 \times 10^{5}\right)$ from DR4 Tg, and transplanted by tail vein injection into previously irradiated (990 rads) DR4 Tg recipient mice. A parallel arm involving Lin- cells (CD45.2, $\left.5 \times 10^{4}\right)$ from TCR Tg mice were similarly combined with unfractionated BM $\left(2.5 \times 10^{5}\right)$ from DR4 Tg mice and transplanted into similarly irradiated hosts. Secondary transplants were generated by injecting $5 \times 10^{5}$ unfractionated BM chimeras from 12 -month-old primary transplants into irradiated DR4 $\mathrm{Tg}$ mice. For humanized transplants, a similar competitive reconstitution was performed using transduced human $\mathrm{CD}^{4} 4^{+} / \mathrm{CD} 38^{-}$cells (hCD45, $\left.5 \times 10^{4}\right)$ combined with unfractionated BM cells $\left(\mathrm{mCD} 45.2,2.5 \times 10^{5}\right)$ from DR4 Tg, and then transplanted by tail vein into previously sublethally (500 cGY) irradiated NS2 mice. Transplanted animals were kept in isolation and treated prophylactically with doxycycline.

Flow cytometry sorting and analysis. At different time points after transplantation, PB cells, splenocytes, or thymocytes were collected and stained with fluorochrome-conjugated antibodies specific for various murine surface molecules and analyzed by multicolor flow cytometry to determine percent frequency. To determine gene-specific T cell frequency, we used a combination of antibodies against CD45 (FITC; eBioscience), CD45.1 (FITC; eBioscience), CD3 (PE Cy5; BD Biosciences), CD4 (APC; BD Biosciences), CD8 (Pacific Blue; eBioscience), CD25 (PE Cy7; eBioscience), Foxp3 (Pacific Blue; eBioscience), murine TCR $\beta$ (PE Cy5; BD Biosciences), and the DR4 pentamer containing either the Tyrp $1_{277-297}$ epitope (Ultimer; Tyrp1 Ultimer) or the control gp100 ${ }_{44-59}$ epitope (gp100 Ultimer) (31) (both PE-labeled; ProImmune). To determine T cell activation status, a combination of antibodies against CD4 (APC), Tyrp1 Ultimer (PE), CD44 (PE Cy5; eBioscience), CD45RB (FITC; eBioscience), and CD62L (Pacific Blue; eBioscience) was used. To determine frequency of post-transplant human mononuclear cells following transplantation into NS2 mice, splenocytes were column enriched for human CD45 expression (Miltenyi Biotec), then stained with antibodies to human CD45 (PE Cy5; BD Biosciences), human CD3 (FITC; eBioscience), human CD4 (APC; BD Biosciences), human CD8 (Pacific Blue; eBioscience), and Tyrp1 Ultimer (PE).

IHC. Skin or tumor samples were fixed in formalin and embedded in paraffin or snap frozen in liquid nitrogen. Standard H\&E staining was done on all specimens. For skin samples, blocks were stained with S100 (rabbit polyclonal 1:1,000; Dako; Envision Rabbit Polymer DAB), CD3 (rabbit polyclonal 1:200; Dako; Envision Rabbit Polymer DAB), or human TCR- $\beta$ (mouse IgG1 1:50, Santa Cruz Biotechnology Inc.; Envision Rabbit Polymer $\mathrm{DAB})$. Skin samples were also frozen in liquid nitrogen and stained with antibodies to CD4 (RM4-5 1:500; Serotec; donkey anti-rat DAB) and CD8 (169.4 1:200; Serotec; donkey anti-rat DAB). For tumor samples, blocks were stained with CD3 (Envision Rabbit Polymer NovaRED), or human TCR- $\beta$ (Envision Rabbit Polymer NovaRed). 
Determination of LV-TCR gene expression. gDNA was isolated from $1 \times 10^{5}$ BM cells obtained from 6-month secondary transplant recipients (both LV-TCR and control). A qPCR analysis using ABI One-Step Real-Time PCR System (Applied Biosystems) was then performed using a custom designed TaqMan probe (Applied Biosystems) specific for the $\alpha$-variable chain of the LV-TCR vector. A standard curve was generated by making serial dilutions of plasmid DNA from the LV-TCR. Relative TCR gene expression was based on the amplification of each sample against the standard curve. The PCR reactions were set up with TaqMan PCR Core Reagents (Applied Biosystems) using about $100 \mathrm{ng}$ of gDNA ( $20 \mu \mathrm{l}$ total reaction volume) and amplified at $50^{\circ} \mathrm{C}$ for 2 minutes, then $95^{\circ} \mathrm{C}$ for 10 minutes plus 40 cycles of $95^{\circ} \mathrm{C}$ for 15 seconds and $60^{\circ} \mathrm{C}$ for 1 minute.

Lentivirus integration analysis. gDNA was prepared (Qiagen) from $1 \times 10^{5}$ BM cells obtained from 6-month secondary transplant recipients (both LV-TCR and control). Concentration and purity of the gDNA were determined by spectrometry. All samples showed a 260/280 ratio of 1.7 or greater, indicating a high purity. Sample concentrations varied from 0.400 to $0.0500 \mathrm{mg} / \mathrm{ml}$. The gDNA from transplant recipients were diluted to a concentration of $250 \mathrm{ng} / \mathrm{ml}$. The gDNA samples were then individually digested with Tsp5091 (New England BioLabs) at $65^{\circ} \mathrm{C}$ for 2 hours. Following digestion, gDNA fragments were purified using a MinElute Reaction Cleanup Kit (Qiagen). In short, $150 \mu$ l of elution reaction cleanup (ERC) buffer was added to each sample and transferred to spin columns. Columns were centrifuged for 1 minute at $10,000 \mathrm{~g}$ or higher, and the pass-through was discarded. $750 \mu \mathrm{l}$ of buffer PE was added to each column and spun for 1 minute at $10,000 \mathrm{~g}$ or higher. Passthrough was discarded and the column dried by spinning for 2 minutes at $10,000 \mathrm{~g}$. Purified DNA samples were eluted from columns with $12 \mu \mathrm{l}$ of elution buffer. Primers specific for the LTR region of the LV plasmid were biotinylated with native Pfu DNA polymerase (Invitrogen). Primer extension products were subsequently purified using the ERC kit. Microbeads with covalently attached streptavidin (Dynabeads M-280; Invitrogen) were washed, and $40 \mu \mathrm{l}$ of the bead slurry was added to each biotinylated primer. Beads were subsequently washed and blunt-end adaptors ligated with T4 DNA ligase. Integration sites were then identified by nested PCR: master mix consisting of $2 \times$ Extensor HiFi PCR mix
(Invitrogen) and gDNA fragments were aliquoted into $200-\mu \mathrm{l}$ PCR reaction tubes. The microbead-primer bead slurry $(1 \mu \mathrm{l})$ was added and PCR amplified $\left(94^{\circ} \mathrm{C}\right.$ for 2 minutes, $95^{\circ} \mathrm{C}$ for 15 seconds, $60^{\circ} \mathrm{C}$ for $30 \mathrm{sec}$ onds, $68^{\circ} \mathrm{C}$ for 2 minutes for 30 cycles; $68^{\circ} \mathrm{C}$ for 10 minutes, $4^{\circ} \mathrm{C}$ hold). After the first round of nested PCR, a 1:50 dilution was done from each PCR reaction tube and a second round of nested PCR was performed. Each PCR sample was analyzed by agarose gel electrophoresis. In Figure 9D, "internal control fragment" refers to amplification of the proviral DNA 3' to the 5' LTR; "integration site" refers to amplification of DNA flanking the $3^{\prime}$ LTR (77).

Tumor treatment assays. Six-month-old secondary DR4 Tg transplant recipients in an experimental group (LV-TCR-F2a) and a control group were subcutaneously implanted $\left(5 \times 10^{5}\right.$ cell $\left./ 200 \mathrm{ml} \mathrm{HBSS}\right)$ with B16-DR4 at 5 mice per group. Perpendicular tumor diameters were blindly recorded every 3 days. Mice were sacrificed at 20 days after implantation, and tumors were excised for IHC analysis. Experiments were performed twice in a blinded, randomized fashion, with similar results.

Statistics. Summary data are displayed as statistical mean \pm SEM or a $95 \%$ confidence interval. $P$ values were generated using a Student's $t$ test with a 2 -tailed distribution. A $P$ value of 0.05 or lower was considered significant. For tumor experiments, the statistical significance between groups was based on the perpendicular tumor size, using the 2-tailed Student's $t$ test.

\section{Acknowledgments}

Funding for this research project was supported by grant NIH R01: RCA134014A. The authors would like to thank Steven A. Rosenberg, Wolfgang Leitner, and Keith Lillemoe for all their advice and support.

Received for publication April 8, 2010, and accepted in revised form September 29, 2010.

Address correspondence to: Christopher E. Touloukian, Department of Surgery, Indiana University School of Medicine, 950 West Walnut Street, Research Building II, Room 302, Indianapolis, Indiana 46202, USA. Phone: 317.278.9945; Fax: 317.274.7592; E-mail: ctoulouk@iupui.edu.
1. Dudley ME, Rosenberg SA. Adoptive-cell-transfer therapy for the treatment of patients with cancer. Nat Rev Cancer. 2003;3(9):666-675.

2. Morgan RA, et al. Cancer regression in patients after transfer of genetically engineered lymphocytes. Science. 2006;314(5796):126-129.

3. Gattinoni L, Powell DJ Jr, Rosenberg SA, Restifo NP. Adoptive immunotherapy for cancer: building on success. Nat Rev Immunol. 2006;6(5):383-393.

4. Lanzavecchia A, Sallusto F. Progressive differentiation and selection of the fittest in the immune response. Nat Rev Immunol. 2002;2(12):982-987.

5. Rizzuto GA, et al. Self-antigen-specific CD8+ T cell precursor frequency determines the quality of the antitumor immune response. J Exp Med. 2009; 206(4):849-866.

6. Xie Y, et al. Naive tumor-specific CD4+ T cells differentiated in vivo eradicate established melanoma. J Exp Med. 2010;207(3):651-667.

7. Minang JT, et al. Distribution, persistence, and efficacy of adoptively transferred central and effector memory-derived autologous Simian Immunodeficiency Virus-specific CD8(+) T cell clones in rhesus macaques during acute infection. J Immunol. 2010;184(1):315-326.

8. Gattinoni L, et al. Wnt signaling arrests effector T cell differentiation and generates CD8+ memory stem cells. Nat Med. 2009;15(7):808-813.

9. Gerloni M, Zanetti M. CD4 T cells in tumor immunity. Springer Semin Immunopathol. 2005;27(1):37-48.
10. Knutson KL, Disis ML, Salazar LG. CD4 regulatory $\mathrm{T}$ cells in human cancer pathogenesis. Cancer Immunol Immunother. 2007;56(3):271-285.

11. Sun JC, Williams MA, Bevan MJ. CD4+ T cells are required for the maintenance, not programming, of memory CD8+ T cells after acute infection. Nat Immunol. 2004;5(9):927-933.

12. Williams MA, Holmes BJ, Sun JC, Bevan MJ. Developing and maintaining protective $\mathrm{CD} 8+$ memory $\mathrm{T}$ cells. Immunol Rev. 2006;211:146-153.

13. Brandmaier AG, Leitner WW, Ha SP, Sidney J, Restifo NP, Touloukian CE. High-avidity autoreactive CD4+ T cells induce host CTL, overcome T(regs) and mediate tumor destruction. J Immunother. 2009;32(7):677-688.

14. Ossendorp F, Mengede E, Camps M, Filius R, Melief CJ. Specific T helper cell requirement for optimal induction of cytotoxic $\mathrm{T}$ lymphocytes against major histocompatibility complex class II negative tumors. J Exp Med. 1998;187(5):693-702.

15. Langlade-Demoyen $P$, et al. Role of T cell help and endoplasmic reticulum targeting in protective CTL response against influenza virus. Eur J Immunol. 2003;33(3):720-728.

16. Phan GQ, et al. Immunization of patients with metastatic melanoma using both class I- and class II-restricted peptides from melanoma-associated antigens. J Immunother. 2003;26(4):349-356.

17. Hunder NN, et al. Treatment of metastatic melanoma with autologous CD4+ T cells against NY-
ESO-1. N Engl J Med. 2008;358(25):2698-2703.

18. Matrai J, Chuah MK, VandenDriessche T. Recent advances in lentiviral vector development and applications. Mol Ther. 2010;18(3):477-490.

19. Touloukian CE, et al. Expression of a "self-"antigen by human tumor cells enhances tumor antigen-specific CD4(+) T-cell function. Cancer Res. 2002;62(18):5144-5147.

20. Overwijk WW, et al. Vaccination with a recombinant vaccinia virus encoding a "self" antigen induces autoimmune vitiligo and tumor cell destruction in mice: requirement for CD4(+) T lymphocytes. Proc Natl Acad Sci U S A. 1999;96(6):2982-2987.

21. Bowne WB, et al. Coupling and uncoupling of tumor immunity and autoimmunity. J Exp Med. 1999;190(11):1717-1722.

22. Leitner WW, et al. Alphavirus-based DNA vaccine breaks immunological tolerance by activating innate antiviral pathways. Nat Med. 2003;9(1):33-39.

23. Muranski P, et al. Tumor-specific Th17-polarized cells eradicate large established melanoma. Blood. 2008;112(2):362-373.

24. Morgan RA, et al. High efficiency TCR gene transfer into primary human lymphocytes affords avid recognition of melanoma tumor antigen glycoprotein 100 and does not alter the recognition of autologous melanoma antigens. J Immunol. 2003; 171(6):3287-3295.

25. Zhao Y, Zheng Z, Robbins PF, Khong HT, Rosenberg SA, Morgan RA. Primary human lymphocytes 
transduced with NY-ESO-1 antigen-specific TCR genes recognize and kill diverse human tumor cell lines. J Immunol. 2005;174(7):4415-4423.

26. Van PL, Refaeli Y, Lord JD, Nelson BH, Abbas AK, Baltimore D. Uncoupling IL-2 signals that regulate $\mathrm{T}$ cell proliferation, survival, and Fas-mediated activation-induced cell death. Immunity. 1999;11(3):281-288.

27. Mizuguchi $\mathrm{H}, \mathrm{Xu}$ Z, Ishii-Watabe A, Uchida E, Hayakawa T. IRES-dependent second gene expression is significantly lower than cap-dependent first gene expression in a bicistronic vector. Mol Ther. 2000;1(4):376-382

28. Fang J, et al. Stable antibody expression at therapeutic levels using the 2A peptide. Nat Biotechnol. 2005;23(5):584-590.

29. Cavalieri S, et al. Human T lymphocytes transduced by lentiviral vectors in the absence of TCR activation maintain an intact immune competence. Blood. 2003;102(2):497-505.

30. Kouskoff V, Signorelli K, Benoist C, Mathis D. Cassette vectors directing expression of $\mathrm{T}$ cell receptor genes in transgenic mice. J Immunol Methods. 1995;180(2):273-280

31. Touloukian CE, et al. Identification of a MHC class II-restricted human gp100 epitope using DR4-IE transgenic mice. JImmunol. 2000;164(7):3535-3542.

32. Ohashi PS. Negative selection and autoimmunity. Curr Opin Immunol. 2003;15(6):668-676.

33. Hakim FT, et al. Age-dependent incidence, time course, and consequences of thymic renewal in adults. J Clin Invest. 2005;115(4):930-939.

34. Sfikakis PP, Gourgoulis GM, Moulopoulos LA, Kouvatseas G, Theofilopoulos AN, Dimopoulos MA. Age-related thymic activity in adults following chemotherapy-induced lymphopenia. Eur J Clin Invest. 2005;35(6):380-387.

35. Gallegos AM, Bevan MJ. Central tolerance to tissuespecific antigens mediated by direct and indirect antigen presentation. J Exp Med. 2004;200(8):1039-1049.

36. Bouneaud C, Kourilsky P, Bousso P. Impact of negative selection on the $T$ cell repertoire reactive to a self-peptide: a large fraction of T cell clones escapes clonal deletion. Immunity. 2000;13(6):829-840.

37. Dutton RW, Bradley LM, Swain SL. T cell memory. Annu Rev Immunol. 1998;16:201-223.

38. Stockinger B, Bourgeois C, Kassiotis G. CD4+ memory T cells: functional differentiation and homeostasis. Immunol Rev. 2006;211:39-48.

39. Borrello I, Sotomayor EM, Rattis FM, Cooke SK, Gu L, Levitsky HI. Sustaining the graft-versustumor effect through posttransplant immunization with granulocyte-macrophage colony-stimulating factor (GM-CSF)-producing tumor vaccines. Blood. 2000;95(10):3011-3019.

40. Moyer JS, Maine G, Mule JJ. Early vaccination with tumor-lysate-pulsed dendritic cells after allogeneic bone marrow transplantation has antitumor effects. Biol Blood Marrow Transplant. 2006; 12(10):1010-1019.

41. Gattinoni L, et al. Removal of homeostatic cytokine sinks by lymphodepletion enhances the efficacy of adoptively transferred tumor-specific CD8+ T cells. J Exp Med. 2005;202(7):907-912.

42. Ishikawa F, Saito Y, Yoshida S, Harada M, Shultz LD. The differentiative and regenerative properties of human hematopoietic stem/progenitor cells in NOD-SCID/IL2rgamma(null) mice. Curr Top Microbiol Immunol. 2008;324:87-94.

43. Yang L, Qin XF, Baltimore D, Van PL. Generation of functional antigen-specific $T$ cells in defined genetic backgrounds by retrovirus-mediated expression of TCR cDNAs in hematopoietic precursor cells. Proc Natl Acad Sci U S A. 2002;99(9):6204-6209.

44. Yang L, Baltimore D. Long-term in vivo provision of antigen-specific $T$ cell immunity by programming hematopoietic stem cells. Proc Natl Acad Sci US A. 2005;102(12):4518-4523.

45. Baum C. Insertional mutagenesis in gene therapy and stem cell biology. Curr Opin Hematol. 2007;14(4):337-342.

46. Persons DA. Lentiviral vector gene therapy: effective and safe? Mol Ther. 2010;18(5):861-862.

47. D'Costa J, Mansfield SG, Humeau LM. Lentiviral vectors in clinical trials: Current status. Curr Opin Mol Ther. 2009;11(5):554-564.

48. Cohen CJ, Zhao Y, Zheng Z, Rosenberg SA, Morgan RA. Enhanced antitumor activity of murine-human hybrid T-cell receptor (TCR) in human lymphocytes is associated with improved pairing and TCR/CD3 stability. Cancer Res. 2006;66(17):8878-8886.

49. Bendle GM, et al. Lethal graft-versus-host disease in mouse models of $\mathrm{T}$ cell receptor gene therapy. Nat Med. 2010;16(5):565-570

50. Parish CR. Cancer immunotherapy: the past, the present and the future. Immunol Cell Biol. 2003;81(2):106-113.

51. Rosenberg SA. Development of effective immunotherapy for the treatment of patients with cancer. J Am Coll Surg. 2004;198(5):685-696.

52. Boon T, Coulie PG, Van den Eynde BJ, van der Bruggen P. Human T cell responses against melanoma. Annu Rev Immunol. 2006;24:175-208.

53. Heitger A, et al. Defective T-helper cell function after T-cell-depleting therapy affecting naive and memory populations. Blood. 2002;99(11):4053-4062.

54. Rosenberg SA, et al. IL-7 administration to humans leads to expansion of CD8+ and CD4+ cells but a relative decrease of CD4+ T-regulatory cells. J Immunother. 2006;29(3):313-319.

55. Kameyama K, Vieira WD, Tsukamoto K, Law LW, Hearing VJ. Differentiation and the tumorigenic and metastatic phenotype of murine melanoma cells. Int J Cancer. 1990;45(6):1151-1158.

56. Min B, Yamane H, Hu-Li J, Paul WE. Spontaneous and homeostatic proliferation of CD4 T cells are regulated by different mechanisms. J Immunol. 2005;174(10):6039-6044

57. Mackall CL, Hakim FT, Gress RE. Restoration of T-cell homeostasis after T-cell depletion. Semin Immunol. 1997;9(6):339-346.

58. Krupica T Jr, Fry TJ, Mackall CL. Autoimmunity during lymphopenia: a two-hit model. Clin Immu nol. 2006;120(2):121-128.

59. Ernst B, Lee DS, Chang JM, Sprent J, Surh CD. The peptide ligands mediating positive selection in the thymus control $\mathrm{T}$ cell survival and homeostatic proliferation in the periphery. Immunity. 1999; 11(2):173-181.

60. King C, Ilic A, Koelsch K, Sarvetnick N. Homeostatic expansion of T cells during immune insufficiency generates autoimmunity. Cell. 2004;117(2):265-277.
61. Fry TJ, et al. A potential role for interleukin-7 in T-cell homeostasis. Blood. 2001;97(10):2983-2990.

62. Xu Y, Setaluri V, Takechi Y, Houghton AN. Sorting and secretion of a melanosome membrane protein, gp75/TRP1. J Invest Dermatol. 1997;109(6):788-795.

63. Paulos CM, et al. Microbial translocation augments the function of adoptively transferred self/tumorspecific CD8+ T cells via TLR4 signaling. J Clin Invest. 2007;117(8):2197-2204.

64. Obst R, van Santen HM, Mathis D, Benoist C. Antigen persistence is required throughout the expansion phase of a CD4(+) T cell response. J Exp Med. 2005;201(10):1555-1565.

65. Jelley-Gibbs DM, Brown DM, Dibble JP, Haynes L, Eaton SM, Swain SL. Unexpected prolonged presentation of influenza antigens promotes CD4 T cell memory generation. J Exp Med. 2005; 202(5):697-706.

66. Hu H, Huston G, Duso D, Lepak N, Roman E, Swain SL. CD4(+) T cell effectors can become memory cells with high efficiency and without further division. Nat Immunol. 2001;2(8):705-710.

67. Opferman JT, Ober BT, shton-Rickardt PG. Linear differentiation of cytotoxic effectors into memory $\mathrm{T}$ lymphocytes. Science. 1999;283(5408):1745-1748.

68. Jelley-Gibbs DM, Strutt TM, McKinstry KK, Swain SL. Influencing the fates of CD4 T cells on the path to memory: lessons from influenza. Immunol Cell Biol. 2008;86(4):343-352.

69. Butz EA, Bevan MJ. Massive expansion of antigenspecific CD8+ $\mathrm{T}$ cells during an acute virus infection. Immunity. 1998;8(2):167-175

70. Overwijk WW, et al. Tumor regression and autoimmunity after reversal of a functionally tolerant state of self-reactive CD8+ T cells. J Exp Med. 2003; 198(4):569-580.

71. Quezada SA, et al. Tumor-reactive CD4+ T cells develop cytotoxic activity and eradicate large established melanoma after transfer into lymphopenic hosts. J Exp Med. 2010;207(3):637-650.

72. Touloukian CE, Leitner WW, Robbins PF, Rosenberg SA, Restifo NP. Mining the melanosome for tumor vaccine targets: P.polypeptide is a novel tumor-associated antigen. Cancer Res. 2001; 61(22):8100-8104.

73. Dudley ME, Ngo LT, Westwood J, Wunderlich JR, Rosenberg SA. T-cell clones from melanoma patients immunized against an anchor-modified gp100 peptide display discordant effector phenotypes. Cancer J. 2000;6(2):69-77.

74. Dull T, et al. A third-generation lentivirus vector with a conditional packaging system. J Virol. 1998; 72(11):8463-8471.

75. Salmon P, Kindler V, Ducrey O, Chapuis B, Zubler $\mathrm{RH}$, Trono D. High-level transgene expression in human hematopoietic progenitors and differentiated blood lineages after transduction with improved lentiviral vectors. Blood. 2000;96(10):3392-3398.

76. Liu Y, et al. Identification of parameters required for efficient lentiviral vector transduction and engraftment of human cord blood CD34(+) NOD/ SCID-repopulating cells. Exp Hematol. 2008; 36(8):947-956

77. Smith DR. Ligation-mediated PCR of restriction fragments from large DNA molecules. PCR Methods Appl. 1992;2(1):21-27. 